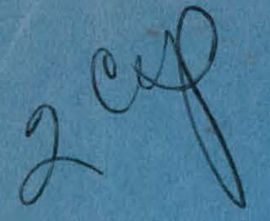

\section{PROTON EXCHANGE RATES AND NUCLEAR MAGNETIC RESONANCE RELAXATION IN AQUEOUS SOLUTIONS OF A HYDROLYTIC TRIMER OF Cr(III) ION}

Ronald Tse Lee

(Ph. D. Thesis)

August 1970

AEC Contract No. W-7405-eng-48 


\section{DISCLAIMER}

This report was prepared as an account of work sponsored by an agency of the United States Government. Neither the United States Government nor any agency Thereof, nor any of their employees, makes any warranty, express or implied, or assumes any legal liability or responsibility for the accuracy, completeness, or usefulness of any information, apparatus, product, or process disclosed, or represents that its use would not infringe privately owned rights. Reference herein to any specific commercial product, process, or service by trade name, trademark, manufacturer, or otherwise does not necessarily constitute or imply its endorsement, recommendation, or favoring by the United States Government or any agency thereof. The views and opinions of authors expressed herein do not necessarily state or reflect those of the United States Government or any agency thereof. 


\section{DISCLAIMER}

Portions of this document may be illegible in electronic image products. Images are produced from the best available original document. 

sponsored by the United States Government. Neither the United States nor the United States Atomic Energy Commission, nor any of their employees, nor any of their contractors, subcontractors, or their employees, makes any warranty, express or implied, or assumes any legal liability or responsibility for the accuracy, completeness or usefulness of any information, apparatus, product or process disclosed, or represents that its use would not infringe privately owned rights.

\section{A BSTRACT}

I. INTRODUCTION-

A. Preliminary Considerations

B. Comments on the. $\operatorname{Cr}$ (III) System

II. THEORY

A. General Considerations - The Determination of $T_{1}$ and $T_{2}-\cdots$

B. Additional Expressions for Chemical Exchange-_-_....... 8

C. Theoretical Expressions for Nuclear Relaxation-_........ 13

III. EXPERIMENTAI-1

A. Preparation of Solutions-16

B. INR Experimental- 19

IV. RESULTS AND DISCUSSION

A. Introductory Considerations

B. First Coordination Sphere Effects- 33

C. Second Coordination Sphere Effects-a 46

D. ' Summary-1-1-

ACKNOWLEDGEMENIS -

REFERENCES -

A.PPISNDIX I-

IIGURE CAPTIONS-

FIGURES - - - 70

DISTRUBOTIUN OF TIUS OOCUMENT IS UNLLWTEE

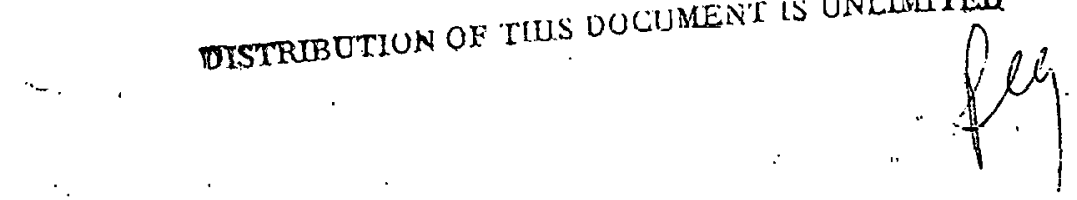


THIS PAGE

WAS INTENTIONALLY

LEFT BLANK 
PROTON EXCHANGE RATES AND NUCLEAR MAGNETIC RESONANCE RELAXATION IN AQUEOUS SOLUTIONS OF A HYDROLYTIC TRIMER OF $\mathrm{Cr}$ (III) ION

\section{Ronald Tse Lee}

Inorganic Materials Research Division, Lawrence Radiation Laboratory and Department of Chemistry, University of California, Berkeley Berkeley, California

\section{ABSTRACT}

The temperature dependence of the transverse NMR relaxation time of protons in aqueous solutions containing a hydrolytic trimer of $\mathrm{Cr}$ (III) . has been studied as'a function of acidity at 60 and $100 \mathrm{MHz}$. The temperature dependence of the longitudinal relaxation time in these solutions at $11 \mathrm{MHz}$ has also been studied as a function of acidity. The chemical shifts of the bulk proton signal with respect to pure water were measured as a function of temperature at $60 \mathrm{MHz}$ to gain additional information.

At the highest temperatures and acidities, the overall rate of relaxation is controlled primarily by the rate of relaxation of a proton while it is in the first coordination sphere of the paramagnetic entity. The particular relaxation mechanism for $\mathrm{T}_{1}$ is interpreted as being a dipoledipole interaction interrupted by rotation and electronic relaxation. The mechanisms found to be operative for the $T_{2}$ data are scalar coupling interrupted by electronic relaxation and dipole-dipole coupling interrupted by rotation and electronic relaxation. It is found that the $\Delta$ mechanism also makes a contribution. By decreasing both the acidity and temperature, the overall relaxation can be made to be controlled by the slowness of chemical exchange of protons from the first coordination sphere, where it is found that a two term rate law is needed to describe the exchange. The relevant parameters for the exchange process have been evaluated. 
coordination sphere becomes important, and it is thought that dipoledipole coupling interrupted by water exchange and rotation is the mechanism of relaxation in this region. 


\section{INIRODUCTION}

\section{A. Preliminary Considerations}

The effects of paramagnetic salts on the longitudinal and transverse relaxation times $\left(\mathrm{T}_{1}\right.$ and $\mathrm{T}_{2}$ ) of protons in aqueous solutions have been a subject of study for almost as long as nuclear magnetic resonance itself. ${ }^{1}$ And much of the treatment of the interactions of the paramagnetic cation with the solvent water molecules, by means of exchange from the first coordination sphere, was developed with respect to protons. ${ }^{2-4}$ More recently these investigations have been extended to $0^{17} \mathrm{NMR}{ }^{5,6}$ since in most previous cases with proton NMR, ambiguities arose as to whether whole water molecules were exchanging or just the protons. 7 In the case of certain paramagnetic species, such as complexes of $\operatorname{Cr}$ (III), where the rate of water exchange is known to be slow, ${ }^{8}$ proton NMR may be used to determine the exchange rates of protons of water molecules in the first coordination sphere with the bulk solvent protons.

MMR may be used as a measure of the rate because of specific strong interactions between the protons of the first coordination sphere with the paramagnetic electrons which shorten the relaxation times $\left(\mathrm{T}_{\mathrm{Im}}\right.$ and $\left.\mathrm{T}_{2 \mathrm{~m}}\right)$ of those protons. If exchange is sufficiently rapid, many protons are allowed to "feel" the presence of the paramagnetic ions, resulting in the shortening of the observed relaxation times $\left(T_{1}\right.$ and $T_{2}$ ) of the bulk solvent. protons. This shortening is controlled by the relative size of two rates: the rate of exchange of a proton from the first coordination sphere to the bulk solvent and the rate of relaxation of a proton when in the first coordination sphere. If the former governs the decrease in $\mathrm{T}_{1}$ and $\mathrm{T}_{2}$, the system is termed to be in the chemical exchange controlied region. 
An increase in temperature results in yet faster exchange which results in yet a greater decrease of the relaxation times of the solvent protons. This corresponds to a chemical reaction, and a plot of the logarithm of the reciprocal relaxation time vs $10^{3} / \mathrm{T}^{\circ} \mathrm{K}$ obeys an Arrhenius relationship. As the exohange rate increases yet further, a point is reached where $\mathrm{T}_{1}$ and $\mathrm{T}_{2}$ become determined primarily by the slowness of the relaxation when in the first coordination sphere. This is known as the relaxation controlled region, and further temperature increases yield information both on the specific interactions causing the relaxation and on the interruption processes for these interactions. Obviously, the foregoing discussion implies that the relaxation times are studied as a function of temperature.

The purpose of this investigation was to determine the rate of proton exchange from a hydrolytic trimer of $\mathrm{Cr}$ (III), thought to be $\mathrm{Cr}_{3}(\mathrm{OH})_{4}{ }^{5+}$ as well as its relaxation mechanisms, and to compare the resullts with those of the hexaaquo species, $\mathrm{Cr}\left(\mathrm{H}_{2} \mathrm{O}\right) \frac{3_{6}^{+}}{6^{+}}$Accordingly, the transverse relaxation times at $60 \mathrm{MHz}$ and $100 \mathrm{MHz}$, the contact shifts at $60 \mathrm{MHz}$, and the longitudinal relaxation times at $11 \mathrm{MHz}$ were studied as a function of temperature and acidity.

\section{B. Comments on the $\mathrm{Cr}$ (III) System}

The proton NMR of $\mathrm{Cr}$ (III) in aqueous solutions has been studied extensively. 4,7,9-13 Unfortunately, many of the early investigators were unaware that the system was appreciably in the exchange controlled region at room temperature and their interpretations were accordingly incorrect. More recently, Bloembergen and Morgan ${ }^{11}$ correctly accounted for the slowness of exchange, while swift and Stephenson ${ }^{12}$ determined that the rate of proton exchange could be expressed as a two term rate law with one term 
being directly dependent on hydrogen ion concentration, $\left[\mathrm{H}^{+}\right]$, and the other independent of it. Most recently, Melton and Pollak ${ }^{13}$ investigated the system again and accounted for second coordination sphere effects at low temperatures.

The present investigation concerns a study of the proton exchange rate and the relaxation processes which occur in a șolution of a hydrolytic polymer of $\mathrm{Cr}(\mathrm{III})$-- thought to be $\mathrm{Cr}_{3}(\mathrm{OH})_{4^{-}}^{5+} 14$ a hydrolytic dimer is also extant with the structure $\mathrm{Cr}_{2}(\mathrm{OH})_{2}^{4+} \cdot 14,15$ It would seem that a study of the dimer would be more feasible since there are, at most, two different types of exchangeable protons on the water ligands, see Fig. la. (The rate of proton exhange from the hydroxo bridge will be discussed shortly). Unfortunately, there is a proton dependent equilibrium between this doubly bridged dimer to a singly bridged species which also changes as a function of temperature. ${ }^{14}$ At the same time, preliminary investigations showed an acid dependence on the relaxation time which would necessitate a study as a function of temperature and acidity. Since the dimer system would introduce ambiguities as to the contribution from each species, it was thought that the trimer study could be done more easily if there is no such equilibrium or if such an equilibrium can be surpressed. Such seems to be the case, but unfortunately the exact structure of this trimeric complex is not known. The most plausible possible structures appear to be stralght linear, oft'set linear or cyclic as Figs. Ib, Ic and ld show, respectively. Disregarding the bridging groups, the 2 linear models have three different kinds of water molecules in the populations of 4,4 and 2 for a total of 10 water molecules; the cyclic model has only two different kinds, numbering 6 and 3 for a total of 9 water molecules. Thompson 14 
has suggested a linear structure on the basis of magnetic susceptibility measurements and on the premise that a linear structure can more readily give rise to more highly polymerized species; these more aggregated species have been found but not separated nor characterized. There is evidence, however, that this is not the case. One could assume that if the trimer were linear, as the dimer must be, it too would exhibit, a single-double bridge equilibrium as evidenced by a measureable change in the optical spectrum under similar conditions of acidity and concentration. Such appears not to be the case, and one might assume that this is not the case because the molecule is cyclic rather than linear. Experimentally, crystals containing the trimer for $x$-ray diffraction have not been prepared so there is no direct method to elucidate the exact structure of the complex. Nevertheless, an interpretation of the data can be made but with the assumption of one or the other structure.

As was noted above the proton exchange from the bridging hydroxo groups has been excluded from consideration. Schwarzenbach and Magyar 16 have measured the $\mathrm{pK}^{\prime} \mathrm{s}$ of various singly bridged hydroxo dinuclear aquoammine complexes of $\mathrm{Cr}$ (III). Two of these compounds with their reactions and $\mathrm{pK}^{\prime} \mathrm{s}$ follow:

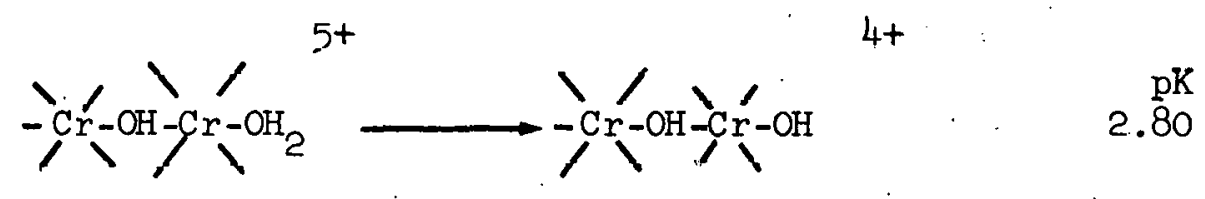
normal erythro basic erythro

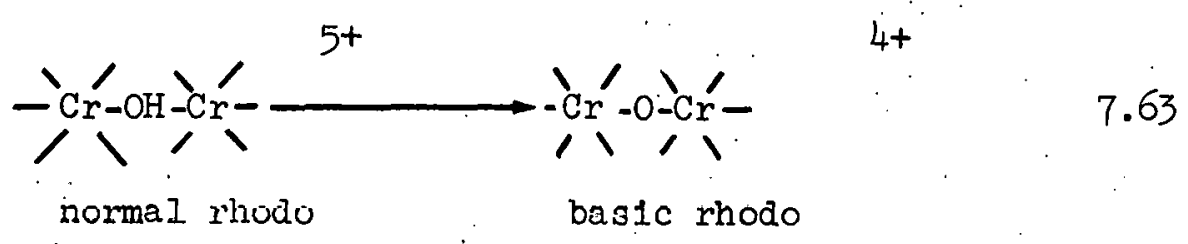

where the dashes filling out the six-fold coordination represent $\mathrm{NH}_{3}$ ligands. 
Since the $K$ is simply the ratio of ( $k_{\text {forward }} / k_{\text {reverse }}$ ), and since $k$ reverse would be expected to be diffusion controlled and therefore about the same in each compound, the ratio of $k_{\text {forward }}$ for the first reaction to that of the second is $\sim 10^{5}$. That is, the rate of proton hydrolysis from the hydroxo bridge is a factor of $\sim 10^{5}$ slower than from a water molecule attached as a ligand to one of the chormium atoms. Susbstituting water molecules for the ammonia ligands probably would not greatly change the relative rates from the bridges and the water ligands, and the ratio of $10^{5}$ should remain about the same. The presence of one additional hydroxo bridging group would tend to reduce further the rate of exchange from a bridge since there is appreciable evidence that in the singly bridged compounds, part of the driving force for removal of a proton from the bridge comes from the tendency of the $\mathrm{Cr}-0-\mathrm{Cr}$ unit to be linear. ${ }^{17}$ The additional bridge prevents such linearity, and the ratio of $10^{5}$ is probably a lower limit to the ratios of exchange. Finally the addition of another chromium atom with its hydroxo bridges to produce a trimeric species should not greatly affect that ratio of $10^{5}$. Such being the case, the ionization rate of a proton from the bridges is expected to be too slow to affect the observed bulk proton relaxation times in the present study.

In the course of this study, however, it was found that the rate law describing the exchange has in it a term dependent on the hydrogen ion concentration which can be identified as some sort of proton addition. There still exists then the possibility of the bridging hydroxo groups participating in exchange by this mechanism, and this possibility will be explored later. 
II. THEORY

\section{A. General Considerations - The Determination of $\mathrm{T}_{1}$ and $\mathrm{T}_{2}$}

In general, there are two methode for the determination of the longitudinal and transverse relaxation times for nuclei. They are continuous wave and pulse methods; each method has its particular area of suitability. 18

For the experiments done: in this laboratory; the transverse relaxation times and chemical shifts were measured using continuous wave spectrometers. The Bloch equations describing the macroscopic properties of nuclei subject to such conditions have been discussed previously. ${ }^{19}$ In particular for the experimental conditions of steady state and slow passage employed in this work on the Varian HA-100 and Varian A-60, the signal observed which is the first side band has the following form: 20

$$
\begin{aligned}
& S=\frac{2 / \beta\left[J_{1}(\beta)\right]^{2} \gamma H_{1} T_{2} M_{0}}{1+\left(\Delta \omega_{+} T_{2}\right)^{2}+\left(\gamma H_{1}\right)^{2} T_{1} T_{2}\left[J_{1}(\beta)\right]^{2}} \\
& \beta=\frac{\gamma H_{m}}{\omega_{m}} ; \Delta \omega_{+}=\omega_{0}-\omega_{m}
\end{aligned}
$$

where

$S \quad$ is the observed signal

$J_{1} \quad$ is the first Bessel Function of theffirst kind

$\gamma$ is the magnetogyric ratio of the nucleus in question

$\mathrm{H}_{1}$ : is one-half the amplitude in gaum of the radio frequency ficld

$\infty$ is the frequency of the radio frequency field in radians/sec

$H_{m}$ is the amplitude of the modulation field in gauss

$\omega_{\mathrm{m}}$ is the frequency of the modulation field in radians/sec

$\omega_{0}$ is the precessional frequency of the nuclei 
$M_{O}$ is the equilibrium magnetization of the sample

$T_{1}$ is the longitudinal or spin lattice relaxation time

$\mathrm{T}_{2}$ is the transverse relaxation time

For conditions of negligible saturation where $\left(\gamma \mathrm{H}_{1}\right)^{2} \mathrm{~T}_{1} \mathrm{~T}_{2}\left[\mathrm{~J}_{1}(\beta)\right]^{2}$ $\ll 1$; the equation reduces to

$$
S=\frac{2 / \beta\left[\mathrm{J}_{1}(\beta)\right]^{2} \gamma_{1} \mathrm{H}_{1} \mathrm{~T}_{2} \mathrm{M}_{0}}{1+\left(\Delta \omega_{+} \mathrm{T}_{2}\right)^{2}}
$$

Experimentally the external magnetic field $\mathrm{H}_{0}$ is swept slowly through the signal. According to the Larmor condition $\omega_{0}=\gamma \mathrm{H}_{0}$, so that $\omega_{0}$ is swept. Since $\Delta \omega_{+}=\omega_{0}-\omega+\omega_{m}, \Delta \omega_{+}$varies and the equation for the signal is evidently that of a Lorentzian line where the resonance condition is for $\Delta \omega_{+}=0$ where $\omega_{f}=\omega-\omega_{m}$. Hence

$$
\frac{1}{T_{2}}=\frac{8}{2}
$$

where 800 is the full line width at the halt-maximum of the signal. The Varian HA-100 and A-60 spectrometers feature special locking devices to prevent field drift. Calibration of the chart sweep width can be done by applying audio-frequency side-bands to any sharp NMR signal. Measuring the exact distances in centimeters. of the side bands from the center NMR signal on the chart paper and measuring the exact audio-frequency with a counter allow one to calculate a ealibration factor in $\mathrm{Hz}$ per centimeter. Multiplication by $2 \pi$ yields the calibration factor in radians/sec per $\mathrm{cm}$. Simultaneously, the linearity of the sweep can be checked.

The longitudinal relaxation times, $\mathrm{T}_{1}$, at $11 \mathrm{MHz}$ were measured using a pulse spectrometer with a $180^{\circ}-90^{\circ}$ pulse sequence. $21-23$

The solution to the Bloch equations for the $z$-component of magnetization is simply: 


$$
M_{z}(t)=M_{0}\left(1-2 e^{-t / T_{1}}\right)
$$

where $t$ is the time interval between the $180^{\circ}$ and $90^{\circ}$ pulse.

$M_{z}(t)$ is the magnetization in the $z$-direction

$\mathrm{M}_{0}$ is the equilibrium magnetization in the $\mathrm{z}$-direction

Rearranging the above equation yields

$$
\frac{M_{0}-M_{z}(t)}{2 M_{0}}=e^{-t / T_{1}}
$$

and

$$
\log \left[M_{0}-M_{z}(t)\right]-\log 2 M_{0}=-\frac{t}{2.303 T_{1}}
$$

If $\left[M_{0}-M_{z}(t)\right]$ or a quantity proportional to it is determined as a function of $t$ and then plotted vs $t$ on semi-logarithmic paper, $T_{1}$ can be obtained from the slope of the line. The time interval, $t$, is monitored with a counter. The signals measured, $S_{0}$ and $S_{z}(t)$, are the heights of the free induction decay signals on the oscilloscope and are proportional to the quantities $M_{0}$ and $M_{z}(t)$. In particular, $S_{0}$ is found by neglecting the $180^{\circ}$ pulse or making $t$ long such that $2 e^{-t / T_{1}} \ll 1$.

It is to be noted that at $\mathrm{M}_{\mathrm{z}}(t)=0, \mathrm{~T}_{1}=t / 2 \mathrm{ln}$ 2. Betermining $\mathrm{T}_{1}$ in this manner does not make use of all the available data, and in particular the magnitude of errors is difficult to estimate. Utilization of the slope method allow the use of all the data and allows estimation of the possible limiting slopes and errors.

\section{B. Additional Expressions for Chemical Exchange}

With the introduction of chemical exchange of nuclei between different magnetic environments, there arises the possibility of relating 
the rates of longitudinal and transverse relaxation in terms of rates of exchange from one environment to the other. In particular, the $\mathrm{T}_{1}$ and $\mathrm{T}_{2}$ of the protons in the bulk waters are measured as was stated in the previous section but are now interpreted as they are modified by exchange of the protons in and out of the vicinity of the paramagnetic species. In principle, the $\mathrm{T}_{1}$ and $\mathrm{T}_{2}$ of the protons attached to the waters directly bound to the paramagnetic species could be measured. In practice they are too short to be determined.

McConnell ${ }^{24}$ first treated the condition of chemical exchange, and Swift and Connick ${ }^{6}$ have considered the case for the resonance of the bulk solvent molecules in a dilute solution of paramagnetic ions. For the steady state condition without saturation, they determined that the rate of transverse relaxation is given by

$$
\frac{I}{T_{2}}=\frac{1}{T_{2 H_{2} O}}+\frac{1}{\tau_{H_{2} O}} \frac{\left[1 / T_{2 m}\left(1 / T_{2 m}+1 / \tau_{m}\right)+\Delta w_{m}{ }^{2}\right]}{\left[\left(1 / T_{2 m}+1 / \tau_{m}\right)^{2} \Delta \omega_{m}{ }^{2}\right]}
$$

where

$\tau_{m} \quad$ is the life-time of a proton in the first coordination sphere of the paramagnetic species before exchanging to the bulk.

$\tau_{\mathrm{H}_{2} \mathrm{O}}$ is the lifetime of a proton in the bulk water before exchanging to the first coordination sphere.

$\mathrm{T}_{2 \mathrm{~m}}$ is the transverse relaxation time for a proton in the first coordination sphere willuut exchange.

$\mathrm{T}_{2 \mathrm{H}_{2} \mathrm{O}}$ is the transverse relaxation time for a proton in the bulk waters

$\Delta \omega_{m}$ is the difference in precessional frequency between that of the proton nuclei of the solution and those of the coordinated water molecules. 
The quantity measured is $1 / \dot{T}_{2}$ but the parameter of interest is

$$
\frac{1}{T_{2 p}}=\frac{1}{T_{2}}-\frac{1}{T_{2 H_{2} O}}=\frac{1}{\tau_{H_{2} O}} \frac{\left[1 / T_{2 m}\left(1 / T_{2 m}+1 / \tau_{m}\right)+\Delta \omega_{m}^{2}\right]}{\left[\left(1 / T_{2 m}+1 / \tau_{m}\right)^{2}+\Delta \omega_{m}{ }^{2}\right]}
$$

which is the enchancement of the rate of relaxation of the bulk protons because of exchange with paramagnetic sites.

At exchange equilibrium the rate of exchange of nuclei into the coordinated sites must be equal to the rate of exchange out, so that

$$
\frac{1}{{ }^{\tau_{\mathrm{H}_{2} \mathrm{O}}}}\left(2\left[\mathrm{H}_{2} \mathrm{O}\right]+\left[\mathrm{H}^{+}\right]\right)_{\mathrm{bulk}}=\frac{1}{\tau_{\mathrm{m}}} 2 \mathrm{n}\left[\mathrm{M}^{+\mathrm{q}}\right]
$$

where $\left(2\left[\mathrm{H}_{2} \mathrm{O}\right]+\left[\mathrm{H}^{+}\right]\right)_{b u l k}$ is the molar concentration of protons in the bulk environment; and $2 \dot{n}\left[\mathrm{M}^{+\mathrm{q}}\right]$ is the molar concentration of protons in the first coordination sphere, $\mathrm{n}$ being the coordination number of :the-metal species for the attached waters; and $\left[\mathrm{M}^{+q}\right]$ is the molar concentration of the metal species. Hence we can define

$$
\frac{\tau_{m}}{\tau_{H_{2} O}}=\frac{2 n\left[\mathrm{M}^{+\mathrm{q}}\right]}{\left(2 \cdot\left[\mathrm{H}_{2} \mathrm{O}\right]+\left[\mathrm{H}^{+}\right]\right)}=\mathrm{P}_{\mathrm{m}}
$$

and $\quad I / \tau_{\mathrm{H}_{2} \mathrm{O}}=\mathrm{P}_{\mathrm{m}} / \tau_{\mathrm{m}}$, which yields

$$
\frac{I}{T_{2 p}}=\frac{P_{m}}{\tau_{m}} \frac{\left[I / T_{2 m}\left(I / T_{2 m}+1 / \tau_{m}\right)+\Delta \omega_{m}^{2}\right]}{\left[\left(1 / T_{2 m}+I / \tau_{m}\right)^{2}+\Delta \omega_{m}{ }^{2}\right]}
$$

There are two limiting regions for $1 / \mathrm{T}_{2 \mathrm{p}}$ :

(I) The chemical exchange controłzed region where

$$
1 / \tau_{m} \ll 1 / T_{2 m} \text { or } 1 / \tau_{m} \ll \Delta \omega_{m}^{2} \tau_{m}
$$

in which case the equation reduces to

$$
1 / T_{2 p}=P_{m} / \tau_{m}
$$


(2) the relaxation controlled region where

$$
I / \tau_{m} \gg I / T_{m} \text { and } I / \tau_{m} \gg \Delta \omega_{m}^{2} \tau_{m}
$$

in which case

$$
1 / T_{2 p}=P_{m}\left(1 / T_{2 m}+\Delta w_{m}^{2} \tau_{m}\right)
$$

The two regions can be thought of in terms of two processes which govern the bulk water relaxation times; the rate of migration of a proton away from the vielnty" of a paramagnetic entity and the rate of interaction of that proton with the paramagnetic entity, with the slower of the rates governing the overall process. Hence in the first limit, the rate of proton exchange is very small in comparison to the rate of relaxation so that the rate of bulk relaxation is simply the rate of exchange. The second limit is reached by an increase in the rate of exchange, say by increasing the temperature, so that the rate of interaction is small in comparison to the rate of exchange and the former governs the overall procesi.

Similarly the analogous equation for the rate of ehhancement of the longitudinal relaxation is given by: ${ }^{11}$

$$
\frac{1}{T_{l p}}=\frac{P_{m}}{T_{l m}+\tau_{m}}
$$

where $\mathrm{T}_{1 \mathrm{~m}}$ is the longitudinal relaxation time for a proton in the first coordination sphere without exchange. The same limiting regions apply for $T_{1 p}$ such that

$$
\frac{1}{T_{I p}}=\frac{P_{m}}{\tau_{m}}
$$

for the chemical exchange controlled region where $1 / \tau_{m} \ll 1 / T_{I m}$ and

$$
\frac{1}{\mathrm{~T}_{I p}}=\frac{\mathrm{P}_{\mathrm{m}}}{\mathrm{T}_{\mathrm{m}}}
$$

for the relaxation controlled region where $1 / \tau_{\mathrm{m}} \gg 1 / \mathrm{T}_{1 \mathrm{~m}}$. 
Additional information can be obtained from the shifts of the positions of the bulk water resonances in the presence of paramagnetic ions as compared to the resonance positions in their absence, since 6

$$
\Delta w_{m_{2}}=-\frac{P_{m} \Delta \omega_{m}}{\left(\tau_{m} / T_{2 m}+1\right)^{2}+\Delta \omega_{m}^{2} \tau_{m}^{2}}
$$

where the symbols have been defined previously. 'l'here are also the two limiting regions for the shift:

(1) the exchange controlled region where $I / \tau_{m} \ll 1 / T_{2 m}$ or $I / \tau_{m} \ll \Delta \omega_{m}^{2} \tau_{m}$ in which case the equation reduces to

$$
\Delta \omega_{\mathrm{H}_{2} O}=-\frac{\mathrm{P}_{\mathrm{m}} \Delta \boldsymbol{\omega}_{\mathrm{m}}}{\tau_{\mathrm{m}}^{2} / \mathrm{T}_{2 \mathrm{~m}}{ }^{2}+\Delta i \omega_{\mathrm{m}}{ }^{2} \tau_{\mathrm{m}}{ }^{2}}
$$

I'he first or second term in the denominator may be negligible depending on the relative magnitudes of $1 / T_{2 m}$ and $\Delta \omega_{m}$ :

(2) the relaxation controlled region whore

$$
1 / \tau_{m} \gg, I / T_{2 m} \text { and } I / \tau_{m} \gg \Delta \dot{\infty}_{m}^{2} \tau_{m}
$$

in which case

$$
\Delta \omega_{\mathrm{H}_{2} \mathrm{O}}=-\mathrm{P}_{\mathrm{m}} \Delta \boldsymbol{\omega}_{\mathrm{m}}
$$

It should be noted that the foregoing was derived with the condition of one kind of paramagnetic site exchanging its occupants: with the bulk solution. If there are two or more different kinds of sites, each of the equations can be generalized to include this by writing additional terms each identical in form and each representing the contribution to the overall: relaxation time or shift by each different kind of site, provided that the nurlei do not exchange: adrectly: from one: of the non-bulk sites to a nother. 


\section{Theoretical Expressions for Nuclear Relaxation}

The interactions of protons on waters in the first coordination sphere of a paramagnetic ion which contribute to $1 / \mathrm{T}_{1 \mathrm{~m}}$ and $1 / \mathrm{T}_{2 \mathrm{~m}}$, the rates of longitudinal and transverse relaxation in that environment, are: (a) dipole-dipole, (b) scalar, and (c) anișotropic chemical shift. An additional relaxation mechanism for $1 / T_{2 p}$ is (d) the " $\Delta$ " mechanism.

Since these relaxation phenomena have been discussed previously and their contributions to the relaxation have been derived from the basic Hamiltanians only their forms as used in the interpretation of the NMR data of the present system will be presented.

(a) Dipole-dipole 25-27

$$
\begin{aligned}
& \frac{I}{T_{1 D}}=\frac{S(S+1) \ddot{\gamma}_{I}^{2} \gamma_{S}^{2} \hbar^{2}}{15 r^{6}}\left[6 \tau_{1}+\frac{14 \tau_{2}}{1+\omega_{S}{ }^{2} \tau_{2}{ }^{2}}\right] \\
& \frac{I}{T_{2 D}}=\frac{S(S+1) \gamma_{I}^{2} \gamma_{S}^{2} \hbar^{2}}{15 r^{6}}\left[7 \tau_{1}+\frac{13 \tau_{2}}{1+\omega_{S}{ }^{2}{ }^{2}{ }^{2}}\right]
\end{aligned}
$$

where the excellent assumptions of $a_{I}^{2} \tau_{I} \ll I$ and $\omega_{I} \ll \omega_{S}$ have been made, and where

$$
\frac{1}{\tau_{1}}=\frac{1}{\tau_{m}}+\frac{1}{\tau_{r}}+\frac{1}{T_{1 e}}
$$

and

$$
\frac{1}{\tau_{e}}=\frac{1}{\tau_{m}}+\frac{1}{\tau_{r}}+\frac{1}{T_{2 e}}
$$

$S$ is the spin quantum number for the electrons

$\gamma_{I}$ and $\gamma_{S}$ are the magnetogyric ratios of the protons and electrons, respectively. $r$ is the distance separating the two magnetic dipoles 
$\omega_{I}$ and $\omega_{S}$ are tho precessional frequencies of the protons and electrons, respectively

$\tau_{r} \quad$ is the rotational tumbling time

$\mathrm{T}_{1 \mathrm{e}}$ and $\mathrm{T}_{2 \mathrm{e}}$ are the longitudinal and transverse electronic relaxation times, respectively.

(b) Scalar 28,29

$$
\begin{aligned}
& \frac{1}{T_{1 S}}=\frac{S(S+1)}{3}(A / H)^{2} \frac{2 \tau_{C 2}}{1+\omega_{S}^{2} \cdot \tau_{C 2}^{2}} \\
& \frac{1}{T_{2 S}}=\frac{S(S+1)}{3}(A / \hbar)^{2} \quad\left[\tau_{C 1}+\frac{{ }^{\tau_{C 2}}}{1+\omega_{S}{ }^{2} \tau_{C 2}{ }^{2}}\right]
\end{aligned}
$$

where the assumption that $\omega_{I} \ll \omega_{S}$ has again been made, and where

$$
\frac{1}{{ }^{\tau} \mathrm{Cl}}=\frac{1}{\tau_{\mathrm{m}}}+\frac{1}{\mathrm{~T}_{1 \mathrm{e}}}
$$

and

$$
\frac{1}{{ }^{\prime \prime 2}}=\frac{1}{\tau_{m}}+\frac{1}{T_{\text {Le }}}
$$

$A$ is the scalar coupling constant, and other symbils: have been defined previously:

(c) Arisiotropie: chemical shift 30

$$
\begin{aligned}
& \frac{1}{T_{I A S}}=12 / 40 \omega_{I}^{2} \delta_{z Z}^{2}\left(1+\eta^{2} / 3\right) \tau_{I} \\
& \frac{1}{T_{\text {IAS }}}=14 / 40 \omega_{I}^{2} \delta_{z Z}^{2}\left(1+\eta^{2} / 3\right) \tau_{I}
\end{aligned}
$$

where $1 / \tau_{1}=1 / \tau_{m}+1 / \tau_{r}+1 / T_{l e}$

$8_{z z}$ is the component of the $\beta$ tensor along the $z$-axis of the molecular frame. This corresponds to the Hamiltonian $\left(-\gamma_{0} \vec{H} \cdot \underline{\beta} \cdot \vec{I}\right)$ where $\beta$ is diagonal and traceless. 
$\eta$ is an asymmetry parameter given by $\eta=\frac{\delta_{x x}-\delta y}{\delta_{z z}}$

The: reasonable assumption of extreme narrowing, i.e. $\omega_{I}^{2} \tau_{1}^{2} \ll 1$, has been made.

It is to be noted that the three mechanisms all contribute to the rate of relaxation of the protons in the first coordination sphere accordIng to

$$
\frac{1}{T_{i m}}=\frac{1}{T_{i D}}+\frac{1}{T_{i S}}+\frac{1}{T_{i A S}}
$$

where $i=1$ or 2 .

(d) The " $\Delta \omega^{\prime \prime}$ mechanism 6

It was shown in 13 that in the relaxation controlled limit

$$
\frac{I}{T_{2 p}}=P_{m}\left(I / T_{2 m}+\Delta \omega_{m}^{2} \cdot \tau_{m}\right)
$$

The contribution from the " $\Delta$ " mechanism then is written just as

$$
P_{m} \Delta_{m}{ }^{2} \tau_{m}
$$

From Bloembergen 31 it is known that

$$
\left|\Delta w_{m}\right|+\left|\Delta \omega_{H_{2}^{\prime}}\right|=\omega_{I} S(S+I) \frac{\gamma_{S}}{\gamma_{I}} \cdot \frac{A}{3 k T}
$$

Since for the dilute solutions considered here

then

$$
\left|\frac{\Delta a m}{\Delta a_{\mathrm{H}_{2} \mathrm{O}}}\right|=-10^{3}
$$

$$
\left|\Delta \omega_{m}\right| \cong \omega_{I} \quad(s+I) \frac{\gamma_{S}}{\gamma_{I}} \frac{A}{3 k I}
$$

which is an excellent approximation.

The interpretation of the NMR data is aimed at resolving the contributions from the chemical exchange controlled region and the relaxation controlled region, and evaluating the individual mechanismswhich contribute to the latter. 
III. EXPERIMENTAL

\section{A. Preparation of Solutions}

Solutions of the trimeric polymer of $\operatorname{Cr}$ (III) were prepared by either of two methods.

1. A solution of $\mathrm{Cr}\left(\mathrm{ClO}_{4}\right)_{3}$ which was $\sim 1 \mathrm{M}$ in $\mathrm{Cr}$ was stirred vigorously while small amounts or sol10 $\mathrm{NaHCO}_{3}$ were added lo the sulution as the $\mathrm{pH}$ was monitored. When the $\mathrm{pH}$ reached 3.5 to 1.0 , the addition of $\mathrm{NaHCO}_{3}$ was stopped and the solution was refluxed at least 12 hours. ${ }^{14,32,33}$ Care must be taken as to the amourit of $\mathrm{NaHCO}_{3}$ added; too little results in very little polymerization; too much results in what is thought to be extensive polymerization beyond the trimer stage.

2. A solution of $\mathrm{Cr}\left(\mathrm{ClO}_{4}\right)_{3}$ which was $\sim 0.50 \mathrm{M}$ in chromium was passed through a Jones Reductor to form $\mathrm{Cr}(\mathrm{II})^{32}$. The effluent was collected in a flask with no precaution of excluding atmospheric oxygen. Upon exposure to the $\theta_{2}$ m the atmosphere the $\operatorname{Cr}$ (II) turns a dark green. The solution was left to stand overnight. The resulting solution has $\sim 50 \%$ trimer. It should be noted that extensive oxidation by bubbling $\mathrm{O}_{2}$ through the chromous solution as it emerges from the Jones Reductor leads to $260 \%$ dimer.

The resulting solutions in either method of preparation are mixtures of monomer, dimer, trimer and what is thought to be yet more highly polymerized species.

Separation of the species was effected by the use of ion exchange resin. Dowex resin, AG 50W-X4, 200-400 mesh in the:proton form purchased from Bio Rad Iaboraturies, Richmond, Ca., was prepared for use by adding it as a slurry in $2 \mathrm{M}$ hydrochloric acid to a column $\sim \mathrm{cm}$ 
in diameter. The resin was washed with distilled water until the effluent was free of acid and the red organic decomposition product (a high molecular weight: sulfonate). This water soluble sulfonate has a high optical density in the region of $300 \mathrm{~m} \mu$ and affects the optical spectra of the chromium species if not eliminated.

The mixture of chromium species was then applied to the top of the column until ca. $50 \%$ of the length of the column was occupied. After a thorough washing with distilled water to remove all free acid, $0.3 \underline{M}$ $\mathrm{Th}\left(\mathrm{ClO}_{4}\right)_{4}$ was used in a displacement type elution with a flow rate of $0.10-0.15 \mathrm{ml} / \mathrm{min}$. The species are moved down the column. The $\mathrm{Na}^{+}$ ions and/or $\mathrm{Zn}^{++}$ions come off first and are discarded. Following this are the violet-purple monomer, the blue green dimer, and the green trimer. There are other green species on the resin mich are not moved and which presumably are more highly charged and highly polymerized entities. These latter were ignored and the trimer was collected with care being taken that neither the dimer which preceded nor the thorium ions which followed were included. The result was a solution of pure trimer and hydrogen ions. The visible spectrum of the trimer is known 14 and the concentration of the stock solution emerging from the column can be calculated from the optical densities at 424 and $\$ 82 \mathrm{m \mu}$ where the extinction coeffieients àe 29.4 and. 18.2 pér mole per liter of $\mathrm{Cr}$; respectively. Any mismatch of the calculated concentrations is an indication of impurities by other $\mathrm{Cr}$ species.

NMR solutions were prepared in $10 \mathrm{ml}$. volumetrics by addition of pipetted amounts of stock trimer and addition of acid with dilution to volume. As a final check of the exact composition of the NMR solutions, 
their spectra were taken again on the Cary 14 Spectrophotometer.

To measure the acidity, one $\mathrm{ml}$ aliquots were added to small columns of ion exchange resin, in the hydrogen form. Distilled water was then used to wash off all the displaced free acid which in turn was titrated with base using methyl-red as the indicator. The titration yielded the total positive charges in one $\mathrm{ml}$ of the solution. The contribution to the total charge by the trimer was found by multiplying its concentration by the charge of the species which in this case was five. The difference between the total charge per $\mathrm{ml}$ and the charge per $\mathrm{ml}$ for the trimer is the free acid concentration. This latter is important because the rate of proton exchange was found to be dependent on free acid.

For the determination of the chemical shifts of the NMR resonance, the sodium salt of 3-(trimethysilyl)-propanesulfonic acia, known as Uvasol and purchased from Brinkmann Instruments Inc., Westbury,: L.I., N.Y., was used as an internal standard: The solutions were 0.04 in uvarsol. As a check that Uvasol itself was not being shifted, para-dioxane, distilled from $\mathrm{CaH}_{2}$, was also employed ( $1 \%$ by volume). The results were the same.

Decomposition of the trimer solutions prepared for the NMR experiments was determined by addition of some of the solution to a short column of ion exchange resin. Elution with $-0.5 \mathrm{M} \mathrm{Ca}\left(\mathrm{ClO}_{4}\right)_{2}$ then followed. The $\mathrm{Ca}^{2+}$ elutes the monomer first, the dimer second, and the trimer last. of all -- the three species being separated into discrete bands along the length of the column. ${ }^{14}$ All the effluent just prior to the forward edge of trimer was collected as one fraction, and then the trimer band - itself was collected separately. Since the extinction coefficients of the $\operatorname{Cr}$ (III) state are so small, the collected fractions of Cr(III) solutions 
were oxidized with $\mathrm{H}_{2} \mathrm{O}_{2}$ and base to chromate. The resultant. $\mathrm{Ca}(\mathrm{OH})_{2}$ precipitate was then complexed with $\mathrm{Na}_{2}$ EDTA and the chromium concentrations were determined spectrophotometrically at $372 \mathrm{~m} \mu$ where $\epsilon=4.81 \times 10^{3} .34$ The degree of decomposition was found to be at most $6 \%$ which is a negligible correction.

\section{B. NMR Experimental}

Measurements of $\mathrm{T}_{1}$ were made on a pulse spectrometer at $1 \mathrm{MHz}$ with a $180^{\circ}-90^{\circ}$ pulse sequence as explained previously. 35 The height of the signals was measured on the grid of a Tektronix oscilloscope with a 53/54G plug in unit. The pulse generators were also Tektronix model 163. The repetition time was set at 010 seconds.

The samples were contained in glass tubes which were $9 \mathrm{~mm}$ ID, $11 \mathrm{~mm}$ OD .

The temperature control was effected through use of a Varian EPR temperature control unit which used liquid nitrogen as a cooling source and a regulated voltage thru high resistance wire as a heating source. The temperature unit cooled or heated tank nitrogen which was flowed thru a Dewared sleeve inserted in the NMR transmitter-receiver coil. The temperature in the liquid sample was measured by inserting a copper constantan thermocouple into a thin glass tube which had been sealed at one end and which contained an organic liquid, and inserting the entire thin tube into the larger glass tube which contained the sample. Temperatures were measured both just prior and just after each determination of $T_{1}$ and in no instance did the temperature vary by more than $\pm 1^{\circ} \mathrm{C}$. 
Measurements of linewidths at $60 \mathrm{MHz}$ were made on a Vairian A-60 NMR spectrometer equipped with a variable temperature probe. This is a particularly convenient instrument to use because of an external lock system which prevents field arift. Care was taken such that saturation did not occur, and the time constant on the filtering circuits was not exceeded. Calibration of the sweep widths to convert centimeters to radians/sec was previously explained.

The shifts of the solvent water protons due to the paramagnetic complex were measured using an internal standard. In each case, two solutions were prepared which were identical in acidity and internal standard content. Only one, however, contained the chromium complex. At each temperature the shift of the solvent water relative to the standard was measured for each solution, and the. shift of the bulk water due to the hyperfine interaction was taken to be the difference in the two measured shifts.

Sampiès were contained in standard Varian NMR tubes which were ca. $4.5 \mathrm{~mm}$ OD.

A Varian Variable Temperature Controller Model V-6040 was used to change temperatures. The exact temperature was obtained by measuring the chemical shift between the different sets of protons in a methanol sample for the low temperatures and ethylene glycol al elevated lemperatures. 36 The shifts were measured just before measurements of the paramagnetic samples and also just after. The temperature was normally maintained within $\pm 1^{\circ} \mathrm{C}$.

Linewidths were also determined at $100 \mathrm{MHz}$ on a Varian HA-100 NMR spectrometer. This instrument features an internal lock system to prevent field drift. The locking sample was concentrated $\mathrm{H}_{\partial} \mathrm{SO}_{L}$ which was 
contained in a standard Varian NMR tube. The paramagnetic sample was contained in a Wilmad inner capillary designed to fit snugly inside the larger Varian tube.

Care was taken that saturation did not occur and that the time constant on the filtering circuits was not exceeded. Temperature control below room temperature was effected through merging a split stream of nitrogen, one of which flowed through copper coils immersed in liquid nitrogen. Above room temperature one single stream of nitrogen was flowed through the cold sink but was heated further along in the system with a coil of nichrome wire wrapped around a quartz rod. The exact temperature was determined with the shifts of methanol and ethylene glycol as above, and was maintained within $\pm 1^{\circ} \mathrm{C}$.

In order to obtain measurements of the contribution of trimer to the bulk relaxation time at elevated temperatures without additional ambiguities from monomer decumpusition produtts, the following procedure was adopted: the temperature in the NMR probe would be measured and maintained while the tube containing the sample was thrust into a water bath maintained at the probe temperature. Temperature equilibrium of the sample through agitation is attained rapidly in this manner, as was determined in trial runs with a thermocouple placed inside the tube. When the equilibration was complete, the sample was quickly removed, the tube wiped and immediately placed in the probe, and the measurement taken quickly. At the highest temperatures measurements would be made on a different sample for each temperature, after which each sample would be measured at $20^{\circ} \mathrm{C}$ and compared with a fresh unkeated sample also measured at $20^{\circ} \mathrm{C}$ to gauge the amount of decomposition and degree of reliance to be placed on the measurement at the high temperature. 
It should be noted that $1 / \mathrm{T}_{2 \mathrm{H}_{2} \mathrm{O}}$ and $1 / \mathrm{T}_{1 \mathrm{H}_{2} \mathrm{O}}$ are very small 37 compared to $1 / T_{2}$ an $1 / T_{1}$ of the paramagnetic samples. Hence $I / T_{2}$ and $I / T_{1}$ were taken as $I / T_{2 p}$ and $I / T_{i p} ; i . e$. , the blank to be subtracted was negligible. 


\section{RESULTS AND DISCUSSION}

\section{A. Introductory Considerations}

In the preliminary investigation, it was found that the system could not be brought unambiguously into the limiting regions of either chemical exchange control or relaxation control. The former should occur at low temperatures, but unfortunately second coordination sphere effects contribute greatly here and obscure the first coordination sphere chemical exchange control region. Freezing of the solution limits the accessibility to lower temperatures which would have permitted a complete investigation of the second coordination sphere contribution.

The first coordination sphere relaxation control region, normally attained at elevated temperatures, was likewise not completely reached because of decomposition of the trimer into hexaaquochromiun(III) at these high temperatures. It was expected that like the monomer, ${ }^{12}$ the trimer would have on acid dependent slep in lts rate law describing the proton exchange, and this expectation was fulfuilled. In principle, this acid dependence should be a convenient means of shifting the system completely into the relaxation controlled region since the addition of acid makes $1 / \tau_{m}$ larger. In practice, this was only partially successful because the additional acid accelerated the decomposition rate. It was found, moreover, that at very high acid, $10 \mathrm{M}$ some change of species appeared to be occuring as was evidenced by a marked narrowing of the NMR signals together with a marked change in the optical spectrum of the solutions. In the latter, the maxima were shifted to longer wavelengths and the optical density of the peak at the lower wavelength was reduced by $\sim 15 \%$. The change was found to be reversible within the time required 
to dilute the strong acid ten-fold with immediate measurement thereafter of the optical spectrum, all at room temperature.

It was thought wise, therefore, to maintain a lower acid concentration throughout so that additional species would not contribute more ambiguities to the interpretation. Optical and ultra-violet spectra of all the MMR solutions used conformed within experimental error to that of the trimer. ${ }^{14}$

There is the problem concerning the proton exchange rates from the waters at the different sites. As discussed previously, there are at least two different kinds of water and there may be as many as three, depending on the structure of the trimer. Obviously one expects the proton exchange rates, both the hydrolysis or ionization mechanism and the proton addition mechanism, to be different for these different waters. (The proton ionization mechanism from the bridges has already been discussed in Section I and assumed to be negligible.) Initially it had been hoped that the experimental data might give evidence of more than one sițe exchanging as has been found for water exchange from a Ni(II) complex with two different kinds of water, using oxygen-17 resonance. 38 Unfortunately, the data for the present system do not show any clean-cut evidence of different sites.

The simplest treatment was to assume that the ionization rates are the same for each site, as well as the proton addition rates for each site, and to attempt to fit the data with a consistent set of parameters. Since the approach was reasonably successful in treating the data, it provides some evidence that the hypothesis is essentially correct, although not conclusively so. One might expect the proton ionization rates from the different sites to be nearly the same if these rates are determined primarily by the fact of the attachment of their waters to a chromium (III) 
atom, which means that effects arising from adjacent chromium atoms are not important. The same can be said of the proton addition mechanism. If true, the two rates for trimer should be quite close to the corresponding two rates for monomer, at least within an order of magnitude. Assuming that the number of exchanging protons is 20 for the trimer (the use of this particular number will be discussed shortly), the ratio of $k_{1}$ for monomer 13 to $k_{1}$ for trimer ( $k_{1}$ is defined as the rate constant for ionization) is $\sim 6$ at $25^{\circ} \mathrm{C}$, while the ratio of the $\mathrm{k}_{2} \mathrm{~s}^{12}$ at the same temperature is 0.5 . The ratios do indicate that the original suposition was correct.

Although the exchange mechanism of proton ionization from the bridge has been discussed ànd dismissed, there remains the consideration as to whether the bridging groups participate through a proton addition or concerted proton exchange path. Since the bridging protons are so weakly acidic with respect to the water ligand protons, one might except the bridge hydroxide groups to be that much better a base in accepting protons. Unfortunately there is no way of determining just how important this could be. If it does occur, it could conceivably have a very large rate constant such that the acid catalyzed exchange stepwith the bridges would always be in the relaxation controlled region, resulting in a constant contribution at a given temperature to the overall relaxation. This is rather unlikely, since the data have been resolved neglecting this possibility. Furthermore one would expect a residual chemical shift which one does not observe experimentally at low temperatures. The bridges could participate in the proton addition mechanism with fortuitously about the same rate constant as that for the protons on the bound waters. If that were the case, the value of $k_{2}$ defined for the rate of a specific proton 
would be reduced by $20 / 24$ for the linear species and $18 / 22$ for the cyclic species. For simplicity of treatment, however, it will be assumed that exchange. of protons on the bridging groups does not occur rapidly enough to contribute appreciably to the relaxation and chemical shift effects.

Analogously there is also the problem as tb whether the rate of relaxation of a proton on a water molecule in the first coordination sphere is the same in each different site. Again, as in the case of chemical exchange, the rates of relaxation of protons in each site would be the same if these rates are determined primarily by the attachment of the water molecule to the metal atom and effects of adjacent metal atoms areinegijible. It will be found that the important mechanisms for relaxation are dipole-dipole coupling and scalar coupling. From a molecular model, it can easily be seen that the distance of a particular proton to an adjacent chromium atom is approximately twice that of its distance to its own chromium atom. Since the dipolar interaction comes in as $1 / r^{6}$, the effect of an adjacent chromium atom is one part out of sixty-four, which is negligible. The middle chromium atom, assuming the complex is linear, would not be expected to have its dipole moment changed from that of the other chromium atoms. Magnetic susceptability measurements on the trimer have shonw only a small reduction. in the paramagnetism per chromium with respect to the monomer, indicating that there is a little spin interaction through the bridges. ${ }^{14}$ Hence each metal atom acts much as an isolated $\operatorname{Cr}$ (III).

Since the scalar coupling interaction is transmitted. through chemical bonding, one should not expect an appreciable effect between a proton and a neighboring metal atom. It is not unlikely that the scalar coupling of 
the protons with the particular chromium to which that water molecule is attached will be nearly the same for the different chromiums.

In summary then, the data were resolved on the assumption that the different coordinated water molecules all exchange their protons at the same rate and that the protons are relaxed at the same rate in the first coordination sphere.

The complete resolution of all the data, viz., the 'T ${ }_{\text {Ip }}$ 's at $11 \mathrm{MHz}$, the $\mathrm{T}_{2 \mathrm{p}}$ 's at 60 and $100 \mathrm{MHz}$, and the shifts at $60 \mathrm{MHz}$, into the proper contributions was accomplished, and the parameters found to be mutually compatible with each other. The data were interpreted through the following equations, the first two of which are modifications of Eq. 14 and 11 :

$$
\begin{aligned}
& \frac{1}{T_{1 p}}=\frac{P_{m}}{T_{I m}{ }^{+\tau} T_{m}}+\frac{P_{m}(2)}{T_{1 m}(2)} \\
& \frac{1}{T^{2}}=\frac{P_{m}}{\left[\frac{1}{T_{2 m}}\left(\frac{1}{T_{2 m}}+\frac{1}{\tau_{m}}\right)+\Delta w_{m}{ }^{2}\right]} \\
& {\left[\left(\frac{1}{T_{2 m}}+\frac{1}{\tau_{m}}\right)^{2}+\Delta_{m}^{2}\right]} \\
& +\frac{P_{m}^{(2)}}{T_{2 m}(2)} \\
& \Delta \omega_{\mathrm{H}_{2} \mathrm{O}}=-\frac{\mathrm{P}_{\mathrm{m}} \Delta_{\mathrm{m}}}{\left(\frac{{ }_{\mathrm{m}}}{\mathrm{T}_{2 \mathrm{~m}}}+1\right)^{2}+\Delta \omega_{\mathrm{m}}{ }^{2} \tau_{\mathrm{m}}{ }^{2}}
\end{aligned}
$$

where $\mathrm{P}_{\mathrm{m}}$ has been defined as

$$
P_{m}=\frac{\frac{20}{3}\left[\mathrm{Cr}^{3+}\right]}{2\left[\mathrm{H}_{2} \mathrm{O}\right]+\left[\mathrm{H}^{+}\right]}
$$


for the first coordination sphere. The additional terms in Eq. 37 and 38 written for the second coordination sphere effects will be discussed later in this thesis.

Figures 2,3 and 4 show some of the experimental data. The solid. lines correspond to the theoreticàl càlculations using parameters derived as will be explained later.

The procedure of resolving the data involved making educated guesses, assumptions and approximations in the relevant parameters and their temperature dependences. These were used in attempting to fit the data and were subsequently modified and refined by successive approximations. For instance, the fit began with the $\mathrm{T}_{2 \mathrm{p}}$ data at $60 \mathrm{MHz}$. For simplicity the experimental points for each acid concentration were assumed to be described merely by

$$
\frac{1}{T_{2 p} P_{m}}=\frac{1}{T_{2 m}+\tau_{m}}
$$

where this is the form the first term of Eq. 38 takes when the Nas term is negligible. It was assumed that the rate law for exchange could be written as:

$$
\frac{I}{\tau_{m}}=k_{1}+k_{2}\left[\mathrm{H}^{+}\right]
$$

The rate constants $k_{1}$ and $k_{2}$ were assigned various values of $\Delta H^{\ddagger}$ 's and $\Delta S^{\ddagger} \mathrm{s}$, and using these a family of lines of $1 / \tau_{\mathrm{m}} \mathrm{vs} .10^{3} / \mathrm{T}^{\circ} \mathrm{K}$ were prepared, differentiated only by the varying acid concentrations. $\mathrm{T}_{2 \mathrm{~m}}$ should be the same or almost the same for all the acid concentrations at a given temperature and colild be calculated from

$$
T_{2 p} P_{m}-\tau_{m}=T_{2 m}
$$


Doing this for all temperatures should yield the temperature dependence of $\mathrm{T}_{2 \mathrm{~m}}$. To the degree that the results are inconsistent, the assumptions originally made were incomplete or erroneous. Second coordination sphere effects must also be considered as well as the contribution from the " $\Delta$ " mechanism. The contribution by the $\Delta \infty$ mechanism to the te of relaxation in the first coordination sphere according to Eg. 13 can be calculated if $A$, the scalar coupling constant, is known, assuming the temperature dependence of $\tau_{m}$ is also known. In principle, if the shift data can be taken to high temperatures, then according to Eqs. 19 and 36 ,

$$
\Delta a_{\mathrm{H}_{2} \mathrm{O}}=-\Delta_{\mathrm{m}} \mathrm{P}_{\mathrm{m}} \approx-\omega_{\mathrm{I}} \mathrm{s}(\mathrm{s}+1) \frac{\gamma_{\mathrm{I}}}{\gamma_{\mathrm{S}}} \frac{\mathrm{A}}{3 \mathrm{kT}} \mathrm{P}_{\mathrm{m}}
$$

yielding a value for the product $\mathrm{P}_{\mathrm{m}} \mathrm{A}$. Unfortunately, the system cannot be taken to a high temperature before severe decomposition occurs so that Eq. 17 cannot be simplified but must be used in its entirety. Equation 17 lids $\mathrm{T}_{2 \mathrm{~m}}$ and $\tau_{\mathrm{m}}$ as well as $\mathrm{A}$ as parameters. The choice of values for these parameters in making a theoretical plot to fit the shift data must be consistent with $60 \mathrm{MHz}$ linewidth data.

In this manner with a constant working back and forth between the chemical shift, and width data, a set of parameters as a function of temperature was obtained such that theoretical plots could be made to approximate the experimental data. The parameters so nhtained werc found to be reasonable and internally consistent.

The theoretical plot of the chemical shifts in the region of complete relaxation control yields a product of $\mathrm{KAP}_{\mathrm{m}}$ where $\mathrm{K}$ represents a group of known constants, $A$ is the scalar coupling constant, and $P_{m}$ is defined as 


$$
\mathrm{P}_{\mathrm{m}}=\frac{\mathrm{n} / 3\left[\mathrm{Cr}^{3+}\right]}{2\left[\mathrm{H}_{2} \mathrm{O}\right]+\left[\mathrm{H}^{+}\right]},
$$

where $\mathrm{n}$ is the number of exchanging protons per trimer ion. The scalar coupling constant reflects unpa1red electron density per proton. A/r has already been obtained for the hexequoctromium (III) ion by Melton and Pollak ${ }^{13}$ as $1.32 \times 10^{7} \mathrm{rad} / \mathrm{sec}$., which is in elose agreement with the value obtained by Luz and Shulman. ${ }^{39}$ It was assumed that the sculur coupling constant for the trimer would have as its upper limit the val ue for monomer, and that quite probably the $A / K$ would be the same to a firit approximation. This is probably a good approximation since as mentioned previously magnetic susceptability measurements on the trimeric species have shown only a small reduction in the paramagnetism per chromium with respect to the monomer indicating little spin interaction through the bridges. ${ }^{14}$ This is an indication that drastic changes in the electronic structure have nul laken place. The ocalar ooupling sonstant f'nr t.rimer should be smaller if anything. If twenty is taken to be the number of protons exchanging which would appear to, be the maximum number possible; and if the scalar coupling constant of monomer is used, then the product $\mathrm{KAP}_{m}$ is a maximum, and the correct $\mathrm{KAP}_{\mathrm{m}}$ for the trimer should be equal to this or smaller. In the early stages of fitting the shift data, it was tound that the fltted 'value uf ILAF $m$ tended to be larger than the maximum possible. This fit value can be made smaller, however, by changing $\mathrm{k}_{1}, \mathrm{k}_{2}$, and $\mathrm{T}_{2 \mathrm{~m}}$. In particular it was found that smaller values for $\Delta \mathrm{H}_{I}^{\ddagger}$ tended to make the fitted values of $\mathrm{KAP}_{\mathrm{m}}{ }^{\prime} \mathrm{s}$ larger. The $\Delta \mathrm{H}_{I}^{\ddagger}$ was finally adjusted to $10.6 \mathrm{kcal}$ which led the fitted $\mathrm{KAP}_{\mathrm{m}}$ to be equal to 
the maximum. This is a better procedure than it initially appears to be. From the data by Melton and Pollak ${ }^{13}$ for hexaaquochromium (III), one can derive $\Delta \mathrm{H}_{1}^{\ddagger}$ and $\Delta \mathrm{S}_{1}^{\ddagger}$ as $10.5 \mathrm{kcal}$ and $0.7 \mathrm{eu}$, respectively. For the trimer, one would expect that the enthalpy of activation is less than or equal to. that of monomer since this is a hydrolysis step and the greater charge on the trimer might tend to make the protons more acidic. However, as mentioned above $\Delta \mathrm{H}_{1}^{\ddagger}$ for trimer being less than that of monomer yields val ues of $\mathrm{KAP}_{\mathrm{m}}$ larger than possible, so that $\Delta \mathrm{H}_{1}^{\neq}$for trimer has as its lower bound, $\Delta \mathrm{H}_{1}^{\ddagger}$ of monomer. If there are fewer protons exchanging, then the maximum calculated $\mathrm{KAP}_{\mathrm{m}}$ should be smaller. In order to fit the theoretical plot to this smaller $\mathrm{KAP}_{\mathrm{m}}$, the $\triangle_{\mathrm{H}}^{\ddagger}$ for trimer would have to exceed that of the monomer. But this would be unexpected so that one is left with $\Delta \mathrm{H}_{I}^{\ddagger}$ of trimer being about equal to that of monomer, and $n$, the number of exchanging protons, being equal to twanty. If this assignment of $n$ is correct; then the trimer structure cannot be cyclic, but must he 7inear which would agree with the conclusions of Thompson. This argument is obviously not conclusive, however.

From this fitting of the chemical shift and width data, the temperature dependencies of $k_{1}$ and $k_{2}$ are obtained so that the first coordination sphere $\mathrm{T}_{I p}$ data at $11 \mathrm{MHz}$ can be resolved and $\mathrm{T}_{1 \mathrm{~m}}$ can be found as a function of temperature. With all the data so fitted, it then remains to consider the contributions by the individual mechanisms to the total rèluxation.

Some discussion, however, concerning $k_{1}$ and $k_{2}$ for the trimer as compared to other systems is in order. The following table tabulates some relevant parameters for exchange. 
TABLE I.. Exchange parameters for the first and second order rate constants for proton exchange in solutions of chromic and nickelous ions.

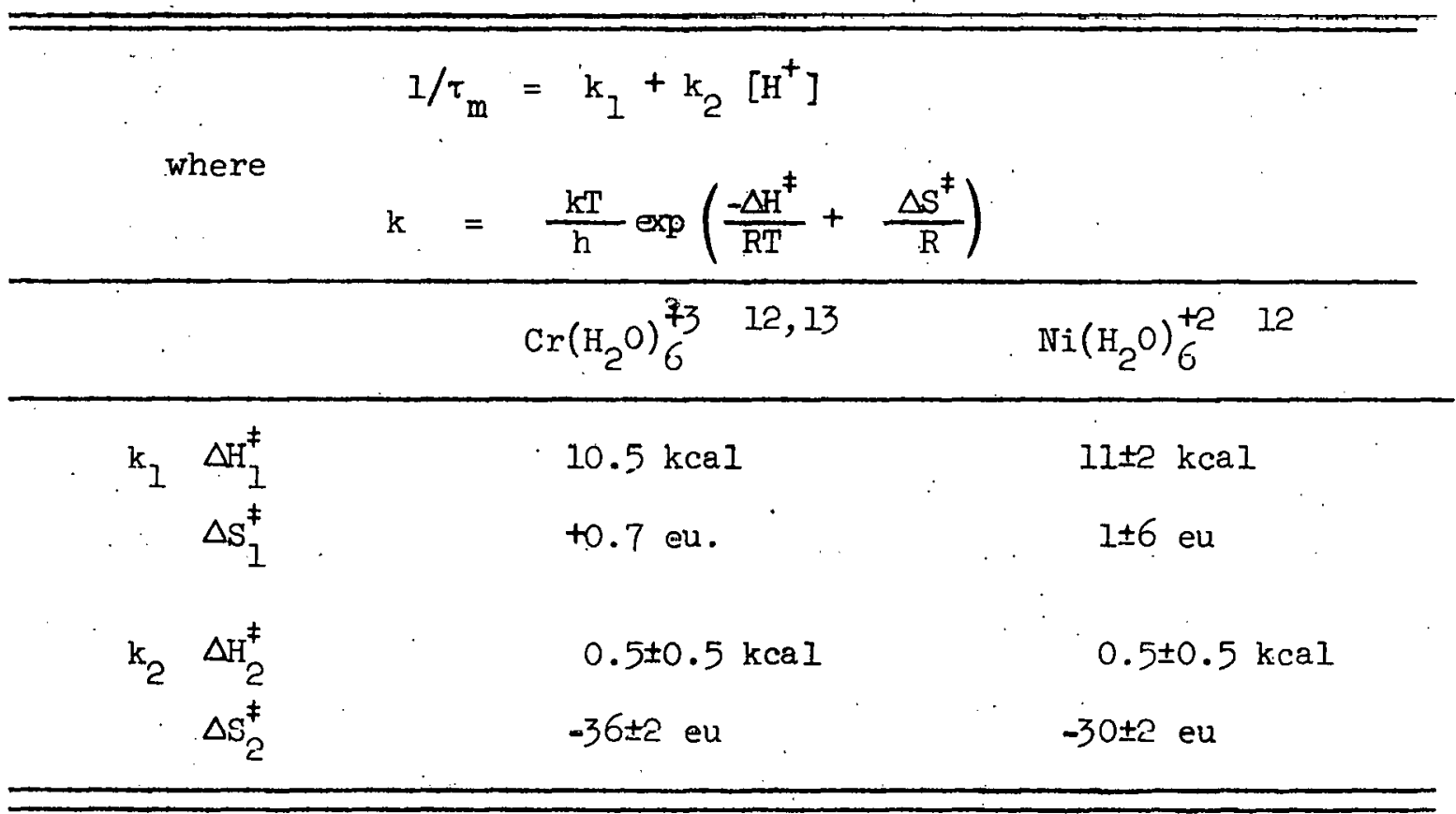

As was mentioned, the temperature dependence of $k_{1}$ for the trimer was adjusted to be very close to that of the monomer in the fitting of

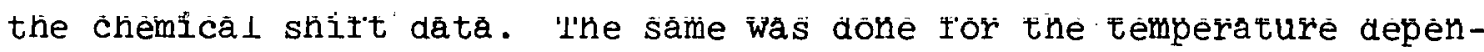
dence of the $\mathrm{k}_{2}$ line. The enthalpies of activation for the $\mathrm{k}^{\prime} \mathrm{s}$ were thus selected to be 10.6 and $0.5 \mathrm{kcal}$ for $k_{1}$ and $k_{2}$, respectively. The entropies of activation were then obtained through the resolution of the other contributions and were found to be -3 eu and -34 eu for $k_{1}$ and $k_{2}$, respectively. These two values compare closely with the corresponding reactions for both $\operatorname{Cr}(\mathrm{III})$ and $\mathrm{Ni}(\mathrm{II})$.

The $k_{1}$ step is essentially a hydrolysis step and describes the following reaction:

$$
\mathrm{Cr}_{3}(\mathrm{OH})_{4}\left(\mathrm{H}_{2} \mathrm{O}\right)_{10}^{+5}+\mathrm{H}_{2} \mathrm{O} \stackrel{\mathrm{k}_{1}}{\longrightarrow} \mathrm{Cr}_{3}(\mathrm{OH})_{5}\left(\mathrm{H}_{2} \mathrm{O}\right)_{9}^{4+}+\mathrm{H}_{3}^{+} \mathrm{O}
$$


The $k_{2}$ step has been proposed by Swift and Stephenson ${ }^{12}$ as being a protonation of one of the water molecules in the complex followed by a rapid deprotonation step. For the monomer they wrote the following set of equations:

$$
\begin{aligned}
& \mathrm{Cr}\left(\mathrm{H}_{2} \mathrm{O}\right)_{6}^{3+}+\mathrm{H}^{*+} \stackrel{3 / 2 \cdot \mathrm{k}_{2}}{\longrightarrow} \mathrm{Cr}\left(\mathrm{H}_{2} \mathrm{O}\right)_{6} \mathrm{H}^{* 4+} \\
& \mathrm{Cr}\left(\mathrm{H}_{2} \mathrm{O}\right)_{6} \mathrm{H}^{* 4+} \stackrel{\text { fast }}{\longrightarrow} \mathrm{Cr}\left(\mathrm{H}_{2} \mathrm{O}\right)_{5}\left(\mathrm{HOH}^{*}\right)^{3+}+\mathrm{H}^{+}
\end{aligned}
$$

where the first reaction is the rate-determining step. The analogous reactions for the trimer are self evident.

\section{B. First Coordination Sphere Effects}

1. $11 \mathrm{MHz}$ Data

From Eq. 37, the following expression is applicable?

$$
\frac{1}{T_{I p}}=\frac{P_{m}}{T_{l m}+\tau_{m}}
$$

where

$$
\frac{1}{T_{I m}}=\frac{1}{T_{I D}}+\frac{1}{T_{1 S}}
$$

The scalar contribution can be shown to be negligible. It can be calculated from Eq. 24 using the A/ just derived, if the correlation time, ${ }^{\tau}{ }_{c 2}$, is known. $\tau_{c 2}$ is just $\mathrm{T}_{2 \mathrm{e}}$ in this case since the rate of transverse electron relaxation will be shown to be $\sim 10^{3}$ times more rapid than the rate of chemical excliarige, (EY. 27). The INMR experiments were done at 11. MHz or 2,586 gauss so that $\mathrm{T}_{2 \mathrm{e}}$ at this field strength is required. No data for $\mathrm{T}_{2 e}$ for trimer exist at this particular field strength, but $\mathrm{T}_{2 \mathrm{e}}$ at $20^{\circ} \mathrm{C}$ has been derived from ESR experiments at $\sim 3300$ gauss, and found to be $1.42 \times 10^{-10} \mathrm{sec} .^{14}$ This value was verified 
by the present investigation. Attempts were made to perform these measurements as a function of temperature, but the solutions were too badly decomposed into monomer, and the latter's ESR spectrum interferes with that of trimer.

What is needed is $T_{2 e}$ at 2,586 gauss as a function of temperature. What is at hand is $\mathrm{T}_{2 \mathrm{e}}$ at 3300 gauss at $20^{\circ} \mathrm{C}$. However, for monomer at concentrations $\sim 3.0 \times 10^{-4} \mathrm{M}$, Melton and Pollak 13 have used the equation developed by Bloembergen and Morgan ${ }^{I I}$ for $I / T_{I}$, the rate of longitudinal electronic relaxation, and have evaluated the constants in it such that $1 / T_{l e}$ can be calculated at any temperature and frequency. The equation is:

$$
\frac{1}{T_{l e}}=1.3 \times 10^{20}\left[\frac{\tau_{v}}{I+\omega_{S}^{2} \tau_{v}^{2}}+\frac{4 \tau_{v}}{I+4 \omega_{S}^{2} \tau_{v}^{2}}\right]^{\prime}
$$

where

$$
\tau_{v}=9.3 \times 10^{-14} \exp \left(\frac{2.1 \times 10^{3}}{\mathrm{RT}}\right)
$$

Both the expression for $\tau_{\mathrm{v}}$ and the constant, $1.3 \times 10^{20}$, were found by an empirical fit of their data.

At the ESR frequency of $9.16 \mathrm{GHz}(\sim 3,200$ gauss $), 1 / T_{2 e}$ for a solution of $\mathrm{Cr}\left(\mathrm{H}_{2} \mathrm{O}\right)_{6}^{3+}$ which was $5 \mathrm{M}$ in chromium has been measured at several temperatures. ${ }^{40}$ At $20^{\circ} \mathrm{C}, 1 / \mathrm{T}_{2 e}$ is found to be $2.3 \times 10^{9} \mathrm{sec}^{-1}$. At the same field where $\boldsymbol{\omega}_{\mathbb{b}}=5.72 \times 10^{10} \mathrm{rad} / \mathrm{sec}$ the calculated value for $1 / T_{\text {le }}$ using the above equation is $1.92 \times 10^{9} \mathrm{rad} / \mathrm{sec}$. Moreover, the calculation shows that the system is in the extreme narrowing condition so that the lower fields, in particular 2,586 gauss, should leave $1 / T_{1 e}$ unchanged. The extreme narrowing condition implies lhat $1 / \mathrm{T}_{2 \mathrm{e}}=1 / \mathrm{T}_{1 \mathrm{e}}$ which is not quite what has been found. At least part of the explanation 
must lie in the fact that Melton and Pollak's conditions were for chromium concentrations of $\sim 10^{-4} \mathrm{M}$. The much greater chromium concentrations used in the ESR measurements surely would decrease $T_{2 e}$ because of intramolecular electronic dipole-dipole and exchange interactions. ${ }^{41}$ In spite of the $10^{4}$ factor in change of concentration, the ratio of $1 / \mathrm{T}_{2 \mathrm{e}}$ (measured) to $1 / \mathrm{T}_{1 \mathrm{e}}=1 / \mathrm{T}_{1 \mathrm{e}}$ (calculated) is only 1.22, and the temperature dependence of the measured $1 / \mathrm{T}_{2 \mathrm{e}}$ follows closely that of the calculated values. Hence, it was taken that the condition of extreme narrowing obtained so that $1 / T_{1 e}=1 / T_{2 e}$ applies at these more dilute chromium concentrations. Assuming now the same functional form for $1 / T_{1 e}$ for trimer, and assuming that the correlation time, $\tau_{\mathrm{v}}$, is the same order of magnitude as that of monomer, then for trimer,

$$
\begin{aligned}
& \frac{1}{\mathrm{~T}_{2 \mathrm{e}}}\left(\begin{array}{l}
\text { measured by ESR at } \\
\sim 3250 \text { gauss at } 0.7 \\
\underline{\mathrm{M} C r 3}+
\end{array}\right) \approx \frac{1}{\mathrm{~T}_{\mathrm{le}}} \\
& =\frac{1}{\mathrm{~T}_{2 e}}\left(\begin{array}{l}
\text { heeded ror MMR at } \\
2586 \text { gauss at } \sim 10^{-2} \\
\underline{M} \text { in } \mathrm{Cr} 3+
\end{array}\right)
\end{aligned}
$$

The temperature dependence found for monomer at 2,586 gauss is then imposed on the measured value of $1 / T_{2 e}$ of trimer. Figure 5 shows this where $I / T_{1 e}=1 / T_{2 e}$.

The calculation of $1 / T_{1 S}$ can now be done and its values are shown in Fig. 6, as a function of temperature.

The dipolar contribution is found to be the dominant term. From Eqs. 22 and 23, to a good approximation:

$$
\frac{1}{\tau_{1}}=\frac{I}{\tau_{2}}=\frac{I}{T_{1 e}}+\frac{1}{\tau_{r}}
$$


since $1 / \mathrm{T}_{1 e}=1 / \mathrm{T}_{2 e}$, and since $1 / \tau_{\mathrm{m}}$ is $\sim 10^{3}$ smaller than either $1 / \mathrm{T}_{1 \mathrm{e}}$ or ${ }^{l / \tau_{r}} \cdot{ }^{\tau}{ }_{r}$ is the rotational tumbling time and is normally taken to obey the Stoke's equation where

$$
\tau_{r}=\frac{4 \pi \mathrm{ma}^{3}}{3 \mathrm{kT}}
$$

where $a$ is the radius of the spherical tumbling entity, $k$ is Boltzmann's constant, $T$ is the temperature in ${ }^{\circ} \mathrm{K}$, and $\eta$ is the viscosity of the solution. For a solution of comparable viscosity as those used in the present investigation, Melton and Pollak have calculated that $\tau_{r}=7.7 \times 10^{-11}$ sec at $25^{\circ} \mathrm{C}$ for monomer. Since the trimer is not a spherical entity, the Stoke's equation cannot be used without modification. It was thought best to take $\tau_{r}$ for trimer as being three times that of monomer. The trimer should tumble around its long axis just like monomer, but probably would change its orientation much more slowly around the other two mutually perpendicular axes which would not contribute significantly to the tumbling rate. Furthermore, it should be noted that the Stoke's equation can be thought of as

$$
\tau_{r}=\mathrm{V} \eta / \mathrm{kT}
$$

where $V$ is the volume. A simple calculation shows that the volume for trimer is $\sim 3$ times that of monomer. The temperature dependence for $I / \tau_{r}$ of trimer is just $T / \eta$. Values of $\eta$ were obtained from the data by Brickweddie. $^{42}$ It was found also that values of $T / \eta$ were virtually identical for all the acid concentrations used in the relevant temperature range, and therefore no additional corrections were needed for the different solutions .

The reciprocal of the correlation time is given in Fig. 5 as well as its component parts. With the temperature dependence of $\tau_{1}=\tau_{2}$ 
now obtained, it is possible to calculate

$$
6 \tau_{1}+\frac{14 \tau_{2}}{1+\omega_{S}{ }^{2} \cdot \tau_{2}{ }^{2}}
$$

as a function of temperature. From Eq. 20

$$
\frac{1}{\mathrm{~T}_{I \mathrm{~m}}} \cong \frac{1}{\mathrm{~T}_{I D}}=\frac{S(S+1) \gamma_{I}{ }^{2} \gamma_{S}{ }^{2} x^{2}}{15 r^{6}}\left[6 \tau_{1}+\frac{14 \tau_{2}}{1+\omega_{S}{ }^{2} \tau_{2}{ }^{2}}\right]
$$

and since $I / T_{I m}$ has been derived from the data, $r$, the dipolar distance, was deduced to be $3.1 \AA$. This seems extraordinarily large. For chromic ion, the sum of the ionic radii for $\mathrm{Cr}$ (III) and $0^{2-}$ yields 2.00 to $2.09 \AA$ as the $\mathrm{Cr}-\mathrm{O}$ distance. ${ }^{43}$ (The range is due to reports of different investigatons).. If the $\mathrm{O}-\mathrm{H}$ distance is taken to be that of the uncoordinated water molecule; $0.96 \AA$, and the $\mathrm{Cr}-\mathrm{O}-\mathrm{H}$ angle taken to be the tetrahedral angle of $109^{\circ} 25^{\prime}$, the calculated $\mathrm{Cr}-\mathrm{H}$ distance is 2.49 to $2.57 \AA$ depending on which ionic radii are used, with $2.53 \AA$ as an average. On the other hand, if the protons on the coordinated water molecule lie in the same plane as the metal atom, the average $\mathrm{Cr}-\mathrm{H}$ distance is $2.74 \mathrm{~A}$.

Melton and Pollak have used a value of $r=2.74 \AA$ to explain and fit their data for the monomer. This dipolar distance was taken from their interpretation of work done by Hausser and Noack, 44 who measured relaxation times in solutions of monomer as a function of frequency such that correlation times could be obtained. These correlation times, however, when used in the dipolar equation yield a distance of $2.55 \AA^{\circ}$.

The applicability of the experiments by Hausser and Noack to Melton and Pollak's work is questionable. The former made no mention of the conditions of acidity, and there may have been appreciable hydrolysis, 
especially at the higher temperatures. Their first order rate constant for proton exchange is a factor of $\sim 3$ greater than that of Melton and Pollak. Their scalar coupling constant is $-33 \%$ less than those reported by Bloembergen and Morgan, ${ }^{11}$ Lus and Shulman, 39 and Melton and Pollak, ${ }^{13}$ these latter three groups of investigators all agreeing closely. Finally Hausser and Noack state that the experimentally determined correlation times do depend on the anion present. Their data were for solutions containing nitrate as the anion whereas the work by Melton and Pollak involved perchlorate.

Since Melton and Pollak have fitted their data for monomer satisfactorily with $r=2.74 \AA$, this will be used as a basis of comparison with the trimer. Taking $r=2.74 \AA$ for the $\mathrm{Cr}-\mathrm{H}$ distance in the trimer system, one can calculate the correlation time from the experimentally derived values. of $1 / \mathrm{T}_{1 \mathrm{~m}}=1 / \mathrm{T}_{1 D^{\circ}}$. Doing so at $25^{\circ} \mathrm{C}$ yields $\tau_{1}=0.22 \times 10^{-10} \sec$ or $I / \tau_{1}=$ 4. $6 \times 10^{10} \mathrm{sec}^{-1}$. Since $1 / \tau_{1}$ is the sum of $1 / \mathrm{T}_{1 \mathrm{e}}$ and $1 / \tau_{r}$, and since $1 / \mathrm{T}_{1 \mathrm{e}}=$ $7 \times 10^{9} \mathrm{sec}^{-1}$, then $1 / \tau_{r}=39 \times 10^{9} \mathrm{sec}^{-1}$, or $\tau_{r}=2.6 \times 10^{-11} \mathrm{sec}$ for the tumbling time. Using the Stoke's equation, Eq. 53, where a is the sum of the ionic radii of $\mathrm{Cr}$ (III) and $\mathrm{O}^{2-}$ and the Van der wals radius of water, this latter being $1.4 \AA$, one calculates that $\tau_{r}$ os $3.7 \times 10^{-11]} \mathrm{sec}$ for monomer at $25^{\circ} \mathrm{C}$. The experimental results have produced a $\boldsymbol{T}_{r}$ for trimer which is even shorter than a calculated one for monomer. which does not seem reasonable.

There is the possibility that fewer than twenty protons are exchanging; the coordination number would then be decreased which would account for the experimentally observed long relaxation time. This approach was tried, but then the chemical shift data yielded a much larger scalar coupling constant. In turn $\mathrm{T}_{\text {le }}$ derived from the data at $14 \mathrm{kG}$ became even 
smaller than the measured $\mathrm{T}_{1 \mathrm{e}}=\mathrm{T}_{2 \mathrm{e}}$ at 3250 gauss. Such a result is impossible if Eq. 49. is correct in describing the electronic relaxation. Equation $49^{\circ}$ is derived from considering that the relaxation is caused by zerofield splitting modulated by a distortion of the octahedral coordination sphere due to molecular collisions and vibrations. This is adequate in explaining the relaxation times for the monomer. However, for the trimer, it may be the case that Eq. 49 is not adequate, but an anisotropic $g$ tensor mechanism modulated by rotation is also important. This latter mechanism has a functional form such that $\mathrm{T}_{1 e}$ is inversely proportional to the square of the field, which would explain why $\mathrm{T}_{\mathrm{le}}$ at $14 \mathrm{kG}$ would be smaller than $\mathrm{T}_{1 \mathrm{e}}$ at 3250 gauss. However, it is unlikely. that this particular mechanism contributes importantly to the relaxation of the trimer because for instance, measurements on even the most distorted of chromic complexes have not shown evidence of anisotropy in the g tensor, and it is unlikely that the trimer would he vary different from the monomer in its electronic structure.

One has three choices in explaining the data: (I) An unusually large dipolar distance; (2) a short tumbling time for the trimer relative to the monomer; (3) fewer protons exchanging but producing an impossibly short $\mathrm{T}_{1 e}$. The first choice might be made possible because the effective charge "felt" by the water molecules is less than three due to the hydrolysis but the lengthening needed is more than expected. None of the above interpretations seem completely satisfactory.

Eithrich and Connick ${ }^{45}$ have hypothesized that a water molecule rotating rapidly along the oxygen-metal bond can give rise to a decrease in the rate of quadrupolar relaxation by averaging the elements of the quadrupolar 
tensor. Perhaps some sort of dipolar averaging is also occurring through. rotational averaging which Eq. 20 does not express, and the decrease in the rate of relaxation in the first coordination sphere would incorrectly . be expressed as an enlarged dipolar distance, both in the case of the monomer and trimer. It is difficult, however, to see how such averaging would produce such a large effect.

The contribution to $\mathrm{T}_{\mathrm{Im}}$ of the anisotropic chemical shift will be discussed with that found for the $60 \mathrm{MHz} \mathrm{T}_{2 \mathrm{~m}}$ work. The second coordination sphere contribution at $11 \mathrm{MHz}$ will also be discussed later.

2. $60 \mathrm{MHz}$ Data

From Eq. 38, the following expression is applicable:

$$
\frac{1}{T_{2 p}}=\frac{P_{m}}{\tau_{m}} \frac{\left[\frac{1}{T_{2 m}}\left(\frac{1}{T_{2 m}}+\frac{1}{\tau_{m}}\right)+\Delta_{m}^{2}\right]}{\left[\left(\frac{1}{T_{2 m}}+\frac{1}{\tau_{m}}\right)^{2}+\Delta_{m}{ }^{2}\right]}
$$

where

$$
\frac{1}{T_{2 m}}=\frac{1}{T_{2 D}}+\frac{1}{T_{2 S}}
$$

The scalar contribution is given in Eq. 25. Since A/K is already known; and since the rates of electronic relaxation are much greater than the rates of exchange (see Eqs. 26 and 27 ), only the values of $T_{\text {l.e }}$ and $\mathrm{T}_{2 \mathrm{e}}$ as functions of temperature are necded. It will be shown further that Eq. 25 can be written simply as

$$
\frac{I}{T_{2 S}}=\frac{S(S+1)}{3} \quad\left(\frac{A}{\hbar}\right)^{2} T_{1 e}
$$

The dipolar contribution is given in Eq. 2l. It will be shown that it also can be simplified and written as 


$$
\frac{1}{T_{2 D}}=\frac{S(S+1) \gamma_{I}{ }^{2} \gamma_{S}{ }^{2} \hbar^{2}}{15 r^{6}} 7 \tau_{I}
$$

where

$$
\frac{1}{\tau_{1}}=\frac{1}{-T_{1 e}}+\frac{1}{\tau_{r}}
$$

Equation 58 can be re-written as

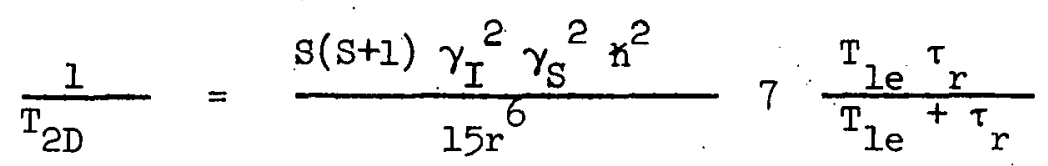

Since values for $r, A / \hbar$ and $\tau_{r}$ have been assumed or are known, and $1 / T_{2 m}$ has been derived from the line fitting, $T_{1 e}$ can be solved for from Eqs. 56, 57 and 60 which produce a quadratic equation in $\mathrm{T}_{1 \mathrm{e}}$. These values of $\mathrm{T}_{l e}$ were smoothed and the reciprocal of the values so produced at $14 \mathrm{kG}$ are shown in Fig. 7 together with those previously assumed for $1 / T_{1 e}$ at 2586, gauss.

As was mentioned previously, an equation for the longitudinal electronic relaxation time of the hexaaquo species has been derived such that $1 / T_{\text {le }}$ can be evaluated at any temperature and frequency. Such values have been calculated as a function of temperature for the ESR frequencies corresponding to $I I$ and $60 \mathrm{MHz}$ for protons. These values a re to be compared with the values derived for the $1 / \mathrm{T}_{1 \mathrm{e}}$ of the trimer at the corresponding frequencies (see Figs. 7 and 8 ).

It can be seen that to the degree that the trimer rate of longitudinal relaxation obeys the same sort of equation, the magnitude and direction of $1 / \mathrm{T}_{1 \mathrm{l}}$ at the two frequencies is approximately correct. In fact the similarity is remarkable considering the errors necessarily introduced in fitting the $\mathrm{T}_{2 \mathrm{~m}}$ line as well as the assumptions made concerning the 
dipolar contribution. If the discrepancies at low temperatures can be discourted, the indication is that the same equation for $1 / T_{1 e}$ applies for the trimer and monomer except for the constant in front of the brackets. This also is logical since the constant reflects the degree of dissymetry in the complex.

Alternatively, it could be said that the discrepancies indicate that the use of the same form of equation is invalid. It should be remembered that in the trimeric complex itself the middle chromium atom certainly "feels" a different environment so that it could have a different relaxation time than the two outer atoms. What would then be "felt" by the protons might be some sort of average of the electronic relaxation times. The possibility of detecting the two scparate relaxation times from the NMR data seems remote considering the large number of parameters already involved.

With a set of values for $I / T_{1 e}$ at this field strength the reciprocal of the dipolar correlation times can be evaluated. Figure 9 shows $1 / \tau_{r}$ from the $11 \mathrm{MHz}$ data and $1 / \mathrm{T}_{1 \mathrm{le}}$ for the $60 \mathrm{MHz}$ field, as well as their sum to yield $1 / \tau_{I}$. The dipolar and scalar contributions to $1 / T_{2 m}$ can be evaluated. Figure 10 shows $1 / T_{2 S}$ and $1 / T_{2 D}$ as well as their sum to yield $1 / \mathrm{T}_{2 \mathrm{~m}}$ at $60 \mathrm{MHz}$.

It was Implied in Eq. 59 that

$$
\mathrm{T}_{1 \mathrm{e}}>>\frac{\mathrm{T}_{2 \mathrm{e}}}{1+\omega_{\mathrm{S}}{ }^{2} \mathrm{~T}_{2 \mathrm{e}}{ }^{2}}
$$

for the $60 \mathrm{MHz}$ proton data at $14 \mathrm{k}$ Gauss. It is known that 


$$
\frac{I}{\mathrm{~T}_{2 \mathrm{e}}} \text { (low field) } \geq \frac{1}{\mathrm{~T}_{2 \mathrm{e}}} \text { (high field) }
$$

and

$$
\frac{1}{\mathrm{~T}_{2 e}} \geq \frac{1}{\mathrm{~T}_{1 \mathrm{e}}} \text { (for any one field) }
$$

then

$$
\frac{1}{\mathrm{~T}_{2 \mathrm{e}}}(3,250 \text { gauss }) \geq \frac{1}{\mathrm{~T}_{2 \mathrm{e}}}(14 \mathrm{kG}) \geq \frac{1}{\mathrm{~T}_{\mathrm{le}}}(14 \mathrm{kG})
$$

or at $25^{\circ} \mathrm{C} \quad \sim 7 \times 10^{9} \mathrm{sec}^{-1} \geq \frac{1}{\mathrm{~T}_{2 \mathrm{e}}}(14 \mathrm{kG}) \geq \sim 3.1 \times 10^{9} \mathrm{sec}^{-1}$

Now if the $1 / \mathrm{T}_{2 \mathrm{e}}(14 \mathrm{kG})$ is just equal to $7 \times 10^{9}$ as the worst case, then $\omega_{\mathrm{S}}^{2} \mathrm{~T}_{2 \mathrm{e}}^{2}=\left(2.48 \times 10^{11} \mathrm{rad} \cdot / \mathrm{sec} \times 1 / \mathrm{T} \times 10^{-9} \sec \right)^{2}=1.26 \times 10^{3}$.

Then

$$
\frac{T_{2 e}}{1+\omega_{S}^{2} T_{2 e}{ }^{2}}=\frac{1 / 7 \times 10^{-9}}{12.6 \times 10^{3}}=1.14 \times 10^{-13}
$$

whore as

$$
T_{1 e}=3.2 \times 10^{10}
$$

and

$$
\mathrm{T}_{\text {l.e }}>>\frac{\mathrm{T}_{2 \mathrm{e}}}{1+\omega_{\mathrm{S}}{ }^{2} \mathrm{~T}_{2 \mathrm{e}}{ }^{2}}
$$

It can been seen that this inequality is valid throughout the temperature range of interest.

It can now also be shown that the simplication used in Eq. 58 for the dipolar relaxation was justified, i.e., that,

$$
7 \cdot \tau_{I}>>\frac{13 \tau_{2}}{1+\omega_{S}^{2} \tau_{2}^{2}}
$$


at $14 \mathrm{kG}$, where.

$$
\frac{I}{\tau_{2}}=\frac{1}{T_{2 e}}+\frac{1}{\tau_{r}}
$$

The value of $I / T_{2 e}$ is not known at $14 \mathrm{kG}$, so $I / \tau_{2}$ is not known. However, $1 / \mathrm{T}_{2 \mathrm{e}}$ is known at 2,586 gauss, and $1 / \mathrm{T}_{2 \mathrm{e}}\left(2586\right.$ gauss) $\geq I / \mathrm{T}_{2 \mathrm{e}}$ (14 kG). Hence

$$
\frac{1}{\tau_{2}}=\frac{1}{\tau_{1}}(\text { at } 2586 \mathrm{G}) \geq \frac{1}{\tau_{2}}(14 \mathrm{kG})
$$

or

$$
\tau_{2}(24 \mathrm{kG}) \geq \tau_{1 \mathrm{~L}}(2586 \mathrm{G})
$$

so that $\tau_{2}(14 \mathrm{kG})$ has a lower limit. From Fig. 5 the smallest value of $\tau_{I}($ at 2,586 gauss $)=9.26 \times 10^{-11} \mathrm{sec}$ at $10^{3} / \mathrm{T}^{\circ} \mathrm{K}=3.50$; the calculation of the denominator in $\mathrm{Eq} .64$ yields:

$$
1+\omega_{S}^{2} r_{1}^{2}=1+\left(2.48 \times 10^{11} \times 9.26 \times 10^{-11}\right)^{2}=529
$$

as a lower limit to $1+\infty_{\mathrm{S}}^{2} \tau_{2}{ }^{2}$ at $14 \mathrm{kG}$. The value of $13 \tau_{p}$ (at $14 \mathrm{kG}$ ) has as its upper 1 im 8 it $13 \tau_{1}$ (at $14 \mathrm{kG}$ ) since $\tau_{2} \leq \tau_{1}$ and the evaluation of $I / \tau_{I}$ at $14 \mathrm{kG}$ has just been done. From Fig. 9 the largest value of $\tau_{1}=0.212 \times 10^{-9}$ at $10^{3} / \mathrm{T}^{\circ} \mathrm{K}=3.75$. is taken as the upper limit of $\tau_{2}$. The calculation follows:

$$
\begin{aligned}
& 7\left(0.212 \times 10^{-9}\right)+\frac{13\left(0.212 \times 10^{-9}\right)}{5.29 \times 10^{2}} \\
& 7\left(0.212 \times 10^{-9}\right)+0.0246\left(0.212 \times 10^{-9}\right)
\end{aligned}
$$

and it is obvious that

$$
7 \tau_{1}>>\frac{1^{13 \tau_{2}}}{1+\omega_{S}^{2} \tau_{2}^{2}}
$$


The approximation is, of course, even better than the calculations indi-cate, since the denominator is at a lower limit and the numerator; at an upper limit.

The $\Delta$ mechanism is found to contribute also to the relaxation rate. The comparison to be made is that of

$$
\frac{1}{T_{2 m}} \text { vs }{\Delta \omega_{m}}^{2} \tau_{m}
$$

The $\Delta_{\infty}$ mechanism becomes strongest at low acidities and low temperatures where $\tau_{\mathrm{m}}$ is long. According to Eq. 36, $\Delta w_{\mathrm{m}}$ can be calculated knowing $A$, the scalar coupling constant. Figure 11 shows the values of $\Delta \omega_{m}^{2} \tau_{m}$ for the different acidities together with $1 / \mathrm{T}_{2 \mathrm{~m}}$.

The contribution of the anisotropic chemical shift to both $1 / T_{I m}$ at $11 \mathrm{MHz}$ and $I / \mathrm{T}_{2 \mathrm{~m}}$ at $60 \mathrm{MHz}$ can be discussed here. The two differ only by a ratio of $6 / 7$. Considering just $1 / T_{2 A S}$

$$
\frac{1}{\mathrm{~T}_{\text {2AS }}}=\frac{14}{40} \cos _{I}^{2} 8_{\mathrm{zz}}^{2}\left(1+\frac{\eta^{2}}{3}\right) \tau_{1}
$$

where $I / \tau_{I}=I / T_{I_{e}}+1 / \tau_{r}$. The validity of the assumption that $\omega_{I}^{2} \tau_{I}^{2} \ll 1$ follows, since from Fig. 9, the largest value of $\tau_{1}$ is $2.1 \times 10^{-10} \mathrm{sec}$, hence $\left(3.77 \times 10^{8} \mathrm{rad} / \mathrm{sec} \times 2.1 \times 10^{-10} \mathrm{sec}\right)^{2}=0.006 \ll 1$. A rough upper limit estimate of $\delta_{\mathrm{zz}}$ can be made by taking

$$
\delta_{z z} \cong \frac{\Delta \omega_{\mathrm{H}_{2} \mathrm{O}}}{\omega_{I} P_{m}}=\frac{\Delta_{\mathrm{m}}}{\omega_{I}}=S(S+1) \frac{\gamma_{S}}{\gamma_{I}} \frac{A}{3 k T}
$$

Then

$$
\begin{aligned}
\frac{1}{T_{2 A S}} & \cong \frac{14}{40} \omega_{I}^{2}\left(S(S+1) \frac{\gamma_{S}}{\gamma_{T}} \frac{A}{3 k T}\right)^{2}\left(1+\frac{\eta^{2}}{3}\right) \tau_{I} \\
& \cong \frac{14}{40} \cdot \Delta_{m}^{2}\left(1+\frac{\eta^{2}}{3}\right) \tau_{I}
\end{aligned}
$$


$\eta \quad$ is on the order of 1 or less, so that

$$
\frac{1}{\mathrm{~T}_{2 A S}} \cong \frac{14}{40} \Delta \mathrm{m}_{\mathrm{m}}^{2} \tau_{1}
$$

This is to be compared with $\Delta_{\mathrm{m}}{ }^{2} \tau_{\mathrm{m}}$. It is obvious that since $\tau_{1}$ is $\sim 10^{4}$ smaller than $\tau_{m}$ the anisotropic chemical shift contribution will be far less than the $\Delta_{\infty}$. The $\Delta_{\infty}$ mechanism is on the order of both the scalar and dipolar mechanisms, so that the $I / T_{2 A S}$ is unimportant. Similarly $I / T_{I D}$ is $\sim 10^{3}$ larger than $1 / T_{I A S}$. Hence the anisotropic chemical shift contributions can be ignored.

\section{Second Coordination Sphere Effects}

Second coordination sphere effects have been invóked previously to explain data in $\mathbb{M M}$ experiments. 46,47 Moreover, experiments designed to study this phenomenon have been carried out. Taube et al. 18 have studied the broadening of the bulk water oxygen-17 resonance in solutions of $\mathrm{Cr}$ (III) where it is known that the first coordination sphere waters are slow to exchange. Connick and Earl ${ }^{49}$. have also studied the chromic system and have evaluated the life-time of a water moledule in the second coordination sphere. Similarly, for proton resonance in $\operatorname{Cr}$ (III) solutions, Melton and Pollak ${ }^{13}$ accounted for a decrease in relaxation time at low temperatures as attributable to second coordination sphere effects.

The $\mathbb{Z}_{2} / \mathrm{T}_{\mathrm{p}}$ proton data of the present system for three acidities of $0.10 ; 0.16$, and $0.19 \mathrm{M}$ perchloric acid at $60 \mathrm{MHz}$ and the $1 / \mathrm{T}_{\mathrm{Ip}}$ data for 0.17 Mperchloric acid at $11 \mathrm{MHz}$ also show a turn-up in the region of low temperature as the first coordination sphere exchange time becomes Iong, (see Fig. 4 and 12). 
The turn-up is attributable to a greater relative importance of interactions of the paramagnetic species with solvent water molecules beyond the first hydration sphere. It can be thought of simply as the exchange of water molecules or protons from the second coordination sphere to the bulk waters with the exchange being so rapid that the contribution is in the relaxation controlled region. The chemical exchange controlled region is ruled out because of the temperature dependence of the contribution. It then becomes necessary to consider what the possible relaxation mechanisms might be. However, it should be borne in mind that the resolved second coordination sphere contribution was found simply by taking a line describing all the interactions in the first coordination sphere, which was calculated using all the foregoing parameters, and subtracting it from the experimental data. The resultant points are small differences between large numbers and contain ali the errors both in the assumed parameters and the experimental data. Therefore the uncertainty of the line formed from these points is quite large, and the interpretalion of the data in this region is subject to the same large uncertainty. The purpose of the following discussion then, is not to obtain quantitative parameters from the data, but to show that the data are consistent with the calculations as to magnitude.

Considering now just the $\mathrm{T}_{2}$ data in $\mathrm{Fig}$. 12, certain relaxation mechanisms can immediately be excluded. Coincident on data taken at $60 \mathrm{MHz}$ on a solution $0.19 \mathrm{M}$ in perchloric acid are data taken at $100 \mathrm{MHz}$ on the same solution. Therefore any mechanism strongly and directly dependent on frequency can be excluded. The $\Delta \omega$ and anisotropic chemical shift interaction can then be assumed to be unimportant. The two mechanisms 
left are scalar and dipolar coupling. The interruption for the scalar coupling if it is important, must involve chemical exchange primarily since the $\mathrm{T}_{\mathrm{le}}$ has been found to be frequency dependent. Likewise, the interruption for the dipolar interaction must be some combination of rotation, chemical exchange, and electronic relaxation with the last being again not too important.

It. should be emphasized that the chemical exchange alluded to in the second coordination sphere is the exchange of whole water molecules to the bulk rather than proton exchange. That this is correct can be shown by considering the relevant rate constants for the monomer and acidic water at $25^{\circ} \mathrm{C}$ contained in the following table.

TABLE II. First order rate constants for water and proton exchange from the first or second coordination sphere of chromic ion

\begin{tabular}{lll}
\hline & $\begin{array}{l}\text { First order rate } \\
\text { constant for proton } \\
\text { exchange in } 0.1 \mathrm{M} \\
\text { acid }\end{array}$ & $\begin{array}{l}\text { First order rate } \\
\text { constant for wa ter } \\
\text { molecule exchange }\end{array}$ \\
\hline First coordination sphere & $0.2 \times 10^{6} \mathrm{sec}^{-1}$ & $4.8 \times 10^{-6} \mathrm{sec}^{-1}$ \\
Second corrdination sphere & $?$ & $3 \times 10^{9} \mathrm{sec}^{-1}$ \\
\hline
\end{tabular}

The rate of proton exchange from the first coordination sphere was taken from the data of Melton and Follak; ${ }^{15}$ (hie water exchange rate frum the first coordination sphere of chromic ion is calculated from Taube's experiments. ${ }^{8}$ The second coordination sphere exchange rate is taken from work done in these laboratories by Earl. 49

The two rates to be compared are proton and water exchange, both from the second coordination sphere. Proton exchange from the second 
coordination sphere other than by water exchange can occur through either a hydrolysis (ionization) mechanism or an acid catalyzed path. The hydrolysis rate is not known but certainly should be less than that for the first coordination sphere (first entry of column one). The acid catalyzed path in water can be calculated from Meiboon's work, 50 who evaluated the rate constants for the following reactions:

$$
\begin{aligned}
& \mathrm{H}_{2} \mathrm{O}+\mathrm{H}_{3} \mathrm{O}^{+} \stackrel{\mathrm{k}_{1}}{\rightarrow} \mathrm{H}_{3} \mathrm{O}^{+}+\mathrm{H}_{2} \mathrm{O} \\
& \mathrm{H}_{2} \mathrm{O}+\mathrm{HO}^{-} \stackrel{\mathrm{k}_{2}}{\rightarrow} \mathrm{HO}^{-}+\mathrm{H}_{2} \mathrm{O}
\end{aligned}
$$

At $25^{\circ} \mathrm{C}, \mathrm{k}_{1}$ and $\mathrm{k}_{2}$ are $(10.6 \pm 4) \times 10^{9}$ liter mole $\mathrm{sec}^{-1}$ and $(3.8 \pm 1.5) \times 10^{9}$ liter mole $\mathrm{sec}^{-1}$, respectively. What is desired, however, is the average time a specific proton is bonded to a specific oxygen atom. The chance that a specific hydrogen atom will be transferred is $1 / 3$ in the first reaction and $1 / 2$ in the second reaction. Hence the specific rate of exchange of a proton is

$$
1 / \tau=1 / 3 \mathrm{k}_{1}\left[\mathrm{H}^{+}\right]+1 / 2 \mathrm{k}_{2}\left[\mathrm{OH}^{-}\right]
$$

For a solution $0.1 \mathrm{M}$ in hydrogen ion, $1 / \tau=(3.5 \pm 1.3) \times 10^{8} \mathrm{sec}^{-1}$ at $25^{\circ} \mathrm{C}$. This would be expected to serve as an upper limit for the acid catalyzed path in the second coordination sphere of chromic ion. Both these values are much smaller than the measured rate of exchange of a water molecule from the second coordination sphere of chromic ion (second entry, Column 2 ). Since the proton rate constants for the first coordination sphere of the trimer are comparable to those of monomer, one expects the same general conclusions to apply. Moreover, evidence will be presented later that the water exchange rate from the second coordination sphere of trimer 
is appreciably greater than for monomer. An upper limit to this might be the reciprocal of the correlation time for translational diffusion of a water molecule in water estimated from the Stoke's equation according to Abragam, 51 where

$$
\tau_{\text {dif }}=\frac{12 \pi \mathrm{a}^{3} \eta}{\mathrm{kT}}
$$

The symbols have been defined previously; the radius a is the Van der Waals radius for water, taken to be $1.4 \AA^{\circ}$. The calculation at $25^{\circ} \mathrm{C}$ yields $1 / \tau_{\text {dif }}=45 \times 10^{9} \mathrm{sec}^{-1}$.

Returning now to consideration of the scalar and dipolar mechanisms, some sort of model concerning the second coordination sphere must be assumed in order to estimate the magnitudes of the two interactions. The models which will be used here is that the trimer is either linear or linear offset and that the water molecules of the second coordination sphere occupy the faces of the octahedra except for the faces which adjoin the shared edges, due to steric factors. This yields a total of sixteen water molecules. Furthermore, since an increase in hydrogen ion concentration also produces an increase in the perchlorate ion concentration, wit will be assumed that at the higher acidities, the perchlorate anions are able to compete effectively for the second coordination sphere sites and tend to exclude water molecules from the faces thereby derreasing the contribution at higher acidities. This assumption is based on the work by Alei ${ }^{52}$ who found that the chemical shifts of the oxygen-17 resonance of the bulk waters in solutions of hexaaquochromium (III), of necessity shifted by interactions in the second coordination sphere, were strongly dependent on perchlorate concentration. He interpreted this as being caused by perchlorate anions excluding water molecules from the faces of the octahedral coordination 
sphere. The effect of a $5+$ charged species should be even greater. It is possible that one perchlorate anion will effectively exclude more than one water molecule so that the effect of perchlorate may be quite significant in decreasing the second coordination sphere contribution.

With this model the relative importance of scalar coupling and dipolar coupling can be estimated. The scalar interaction is unlikely to be much of a contributor. To a large degree scalar coupling from a paramagnetic entity to the second coordination sphere represents bonding between the two since the scalar coupling constant represents unpairèd electron density transmitted through chemical bonding. Although the $t_{2 g}$ electrons are pointed towards the faces of the octahedra, still the degree of chemical bonding between these electrons and ultimately to the protons must certainly be small in comparison to that in the first coordination sphere.

An estimate of the scalar coupling constant for the second coordination sphere protions can he made on the basis of Alei's work with the monomcr. Alei measured the chemical shifts as a function of perchlorate concentration. Using his data, one can extrapolate to zero perchlorate. If one then assumes a coordination number of eight, the resultant scalar coupling constant of $2.36 \times 10^{6} \mathrm{rad} / \mathrm{sec}$ is obtained for oxygen-17. It should be noted that this is an upper limit for the A/h based on a coordination number of eight. A larger coordination number produces a small A/ h. Already, it can be seen that $A / K$ for the oxygen in the second coordination phere is $\sim 1 / 8$ of that for a proton in the first coordination sphere. It is probably a good assumption to take for A/h for protons in the second coordination sphere, a value like $2.4 \times 10^{5} \mathrm{rad} / \mathrm{sec}$. These conclusions for the hexaaquo species should also hold true for the trimer. 
In accordance with this prediction of a small scalar coupling constant for the second coordination sphere protons, no residual shift was detectable in the experimental data for trimer. Moreover, it can be shown that the dipolar interaction will be several orders of magnitude larger than the scalar interaction based on this $\mathrm{A} / \mathrm{h}$.

In estimating the dipolar interaction, one must consider that all the water positions are not alike in the interactions they "feel" from the chromium atoms. For instance, a water resting on the face of the octahedron of the central metal atom would "feel" the effects of the two other metal atoms whereas a water resting on an end face at a terminal chromium would probably "feel" the effects of just that one atom. This effect is relatively more important for the second coordination sphere than for the first, since the rate of change of the dipolar expression with respect to $r$, is just proportional to $I / r^{7}$. That is, for $r$ being small, an increase in $r$ to become $r^{i}$ and raised to the sixth power still makes $1 / r^{6} \gg 1 / r^{6}$. If $r$, however, is already large, the same small increase in $r$ to become $r^{\prime}$ and raised to the sixth power yields $1 / r^{6} \approx 1 / r^{16}$. Hence the interaction of a particular water molecule with more than one chromium atom must be considered to see if it is at all important. The expression. of the dipolar interaction can then be written as:

$$
\frac{1}{T_{2 p}} a \frac{4 \text { waters }}{r_{1}^{6}}+2 \times \frac{4 \text { waters }}{r_{2}^{6}}+\frac{8 \text { waters }}{r_{1}^{6}}+\frac{8 \text { waters }}{6}+\frac{4 \text { waters }}{r_{r}}
$$

The first two terms are written for the four water molecules on the faces of the octahedron of the central chromium atom. The distance $r_{1}$ is just the dipolar distance between the protons on these waters and the chromium 
atom itself, whereas $r_{2}$ is the distance between these protons and the adjacent terminal chromium atoms. The factor of 2 is for the interaction with both end atoms. The next two terms are the interactions of the eight waters on the faces of the terminal chromium atoms, these faces being parallel to the length of the linear trimer. The last term is written for the waters on the end faces of the terminal metal atoms. The expression can be simplified to:

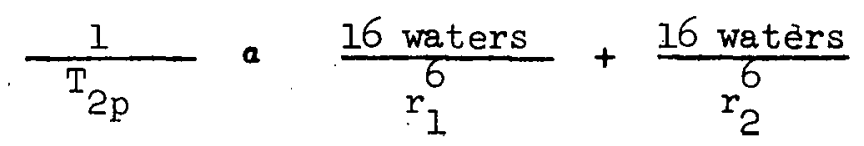

where, of course, $r_{1}<\cdot r_{2}$. Interactions of a proton with a chromium atom further away than an adjacent one have been neglected. One can now estimate the relative ratio of $r_{2} / r_{1}$ using molecular models. This ratio is found to range from 1.5 to 2. Taken to the sixth power, however, the second term ranges in importance from $1 / 11.4$ to $1 / 64$ with respect to the first term. Since at most, consideration of the second term is less than a $10 \%$ correction, it will be neglected. Other assumptions will have at least this magnitude of error.

One is left now with makibg some estimate of the dipolar distance from the protons on water molecules in the second coordination sphere to the chromium atom, and some estimate of the correlation time. Some limits can be set on the value of the correlation time. As mentioned previously, experimentally it was found that the data for a $0.19 \mathrm{M}$ acid solution at 100 and $60 \mathrm{MHz}$ were virtualiy identical at low temperatures in the turn-up region attributed to first coordination sphere chemical exchange control and second coordination sphere relaxation control. Assuming 
that the relaxation is all dipolar, then

$$
\left[\begin{array} { c } 
{ 7 \tau _ { 1 } + \frac { 1 3 \tau _ { 2 } } { 1 + \omega _ { S } { } ^ { 2 } \cdot \tau _ { 2 } { } ^ { 2 } } ] } \\
{ ( \text { at } 6 0 \mathrm { MHz } ) }
\end{array} \quad \approx \cdots \left[\begin{array}{c}
\left.7 \tau_{1}+\frac{13 \tau_{2}}{1+\omega_{S}{ }^{2} \tau_{2}{ }^{2}}\right] \\
(\text { at } 100 \mathrm{MHz})
\end{array}\right.\right.
$$

Since: there is no frequency dependence, the expression becomes

$$
7 \tau_{1} \text { at } 60 \mathrm{MHz} \approx 7 \tau_{1} \text { at } 100 \mathrm{Miz}
$$

Since $\mathrm{T}_{1 \mathrm{l}}$ is frequency dependent, it cannot contribute greatly to $\tau_{1}$. The above equation cannot be in the extreme narrowing region since this would mean. that $\omega_{S}^{2} \tau_{2}^{2} \ll 1$, or at $100 \mathrm{MHz}$ for protons, $\tau_{2} \ll 2.4 \times 10^{-12} \mathrm{sec}^{-1}$ which is physically impossible for any of the correlation times considered here. From Eqs. 67 and 68,

$$
7 \tau_{1} \gg \frac{13 \tau_{2}}{1+\omega_{S}{ }^{2} \tau_{2}{ }^{2}} \text { (at both frequencies) }
$$

Since the rate of exchange is much faster than the electronic relaxation,

$$
\frac{1}{\tau_{1}} \approx \frac{1}{\tau_{2}}=\frac{1}{\tau_{\mathrm{ex}}(2)}+\frac{1}{\tau_{r}}
$$

where $1 / \tau$ ex is the rate of exchange of a water molecule from the second coordination space of the trimer. Then from Eq. 69,

$$
I \gg \frac{1.86}{1+\omega_{S}{ }^{2} \cdot \tau_{1}{ }^{2}}
$$

And for $\omega_{\mathrm{S}}=2.48 \times 10^{11} \mathrm{rad} / \mathrm{sec}$,

$$
1 / \tau \quad 2.7 \times 10^{11} \mathrm{sec}^{-1}
$$

in low temperature turn-up region. However, since $1 / \tau_{1}=1 / \tau_{\text {ex }}^{(2)}+1 / \tau_{r}$, the upper limit for $1 / \tau_{I}$ can be lowered because values for $1 / \tau_{r}$ have 
already been assumed in fitting the first coordination sphere data, and $1 / \tau_{\mathrm{ex}}(2)$ should be less than the rate of water diffusion as used in Eq. 66 . "Since $\tau_{\text {dif }}$ has an $\eta / T R_{K} K$ dependence, it can be evaluated at any temperature. At $25^{\circ} \mathrm{C}$,

or

$$
\frac{1}{\tau_{1}} \approx \frac{1}{\tau_{\text {ex }}(2)}+\frac{1}{\tau_{r}} \leq \frac{i}{\tau_{\text {dif }}}+\frac{1}{\tau_{r}}
$$

$$
\frac{1}{\tau_{\operatorname{ex}}^{(2)}}+\frac{1}{\tau_{r}} \leq 5 \times 10^{10} \mathrm{sec}^{-1}
$$

At the same time, since the electronic relaxation rate is not important,

$$
\frac{1}{\tau_{\text {ex }}^{(2)}}+\frac{1}{\tau_{r}} \gg \frac{1}{T_{\text {Ie }}} \text { (at } 14 \text { kgauss) }
$$

At $25^{\circ} \mathrm{C}, 1 / \mathrm{T}_{1 \mathrm{e}}=3 \times 10^{9} \mathrm{sec}^{-1}$, so that

$$
3 \times 10^{9} \mathrm{sec}^{-1} \ll \frac{1}{\tau_{\text {ex }}^{(2)}}+\frac{1}{\tau_{r}} \leq 5 \times 10^{10}
$$

With the use of molecular models, one can estimate the distance from a central metal to a second coordination sphere proton, allowing for the Van der Wals radii on the first and second coordination sphere waters. The distance estimated is $4.1 \mathrm{~A}$.

Using the equation for the dipolar interaction and the experimentaily determined contribution; correlation times can be calculated using the above dipolar distance. At $25^{\circ} \mathrm{C}$, from Fig. 12, the seoond coordination. sphere contribution to $1 / \mathrm{T}_{2 \mathrm{p}} \mathrm{P}_{\mathrm{m}}^{\text {f }}$ for a $0.1 \mathrm{M}\left[\mathrm{H}^{+}\right]$solution is $0.031 \times 10^{6}$ $\sec ^{-1} \cdot P_{m}^{\prime}$ is defined as 
Correcting for the coordination number by multiplying by $3 / 32$ yields 2. $9 \times 10^{3} \mathrm{rad} / \mathrm{sec}$ for $1 / \mathrm{T}_{2 \mathrm{D}} \cdot$ Then

$$
2.9 \times 10^{3} \mathrm{rad} / \mathrm{sec}=I / T_{2 D}=\frac{S(s+1) \gamma_{I}^{2} \gamma_{S}^{2} \hbar^{2}}{15 r^{6}} 7 \tau_{I}
$$

and $I / \tau_{1}=30 \times 10^{9} \mathrm{sec}^{-1}$ which is within the range of values predicted. Subtracting off the value of $I / \tau_{Y}$, leaves $22.6 \times 10^{10} \mathrm{sec}^{-1}$ for $I / \tau(2)$. Imposing a $\mathrm{T} / \mathrm{m}$ temperature dependence on $1 / \tau_{\mathrm{ex}}(2)$, one can calculate the correlation times for all temperatures. The line drawn in for the second coordination sphere contribution for the $0.10 \mathrm{M}$ acid solution in Fig. 12 was calculated on this basis. Although the data points do seem to lie on the calculated line, the fit is deceptive since the position of the points is subject to such uncertainty as was mentioned previously.

The points for the higher acidities do lie below those of the $0.10 \mathrm{M}$ $\left[\mathrm{H}^{+}\right]$.solutions. Presumably, some perchlorate complexing is occurring which decreases the sites available for relaxation. No effort was made to fit these points except to note their positions with respect to the $0.10 \mathrm{M}$ acid solution.

Using the same correlation time and dipolar distance, a calculated line for the low acid $11 \mathrm{MHz}$ data can be drawn in (see the lower line in Fig. 4). The calculated values lie somewhat above the data points, but since the position of the points themselves is subject to such uncertainty, little is to be gained by reworking the dipolar distance and/or correlation time.

\section{Summary}

It. should be emphasized that the fitting of all the data was done on the assumption that all of the protons on the different waters are 
equivalent; that is, they exchange at the same rate and are relaxed at the same rate. To the degree that this is not the case, the resultant parameters are subject to even more uncertainly. The fact that a fairly satisfactory fit can be obtained using this assumption is evidence in favor of its correctness. No results were obtained that indicated strong differences. in the behavior of the various types of coordinated water molecules.

It is of interest to compare the rate constants for proton exchange of monomer, dimer, and trimer. Some preliminary work was done in the present research on the dimer as a function of temperature at a $\mathrm{pH}$ of $\sim 2$ where the species in solution is virtually all the doubly bridged dimer. 53 Assuming that there are sixteen exchanging protons, where the bridges are again assumed not to contribute to the relaxation, one can estimate the first order rate constant at $25^{\circ} \mathrm{C}$, from a plot of the logarithm of the reciprocal of the relaxation times vs. $10^{3} / \mathrm{T}^{\circ} \mathrm{K}$. The $\mathrm{k}_{1}$ is found to be $9 \pm 2 \times 10^{4} \mathrm{sec}^{-1}$. Since the acidity of the solution is so low, one expects no contribution from $k_{2}$, the acid dependent step. For convenience, all the known rate constants for the three polymers at $25^{\circ} \mathrm{C}$ have been tabulated as well as the charge per chromium atom in each species in Table III.

TABLE III. First and second order rate constants for proton exchange for some $\mathrm{Cr}$ (III) species at $25^{\circ} \mathrm{C}$

\begin{tabular}{lccc}
\hline Spccies & $k_{1}\left(\mathrm{sec}^{-1}\right)$ & $k_{2}\left(\sec ^{-1} \mathrm{M}^{-1}\right)$ & $\begin{array}{c}\text { charge/metal } \\
\text { atom }\end{array}$ \\
\hline Monomer & $17 \times 10^{4}$ & $5 \times 10^{4}$ & 3 \\
Dimer & $(9 \pm 2) \times 10^{4}$ & $9 \times 10^{4}$ & 2 \\
Trimer & $3 \times 10^{4}$ & 9.67 \\
\hline
\end{tabular}


Qualitatively, the trend in the first order rate constants follows what one would expect; the lower the effective charge on the metal, the smaller is the rate constant. The decreased effective charge in the polymers should give a smaller electrostatic repulsion of the protons, thereby decreasing the rate of exchange through the ionization mechanism. Conversely, since the rate determining step in the proton addition mechanism is the addition of a proton to a water of the metal species, the second order rate constant should increase with a smaller effective charge on the metal species. The $\mathrm{k}_{2}$ 's for the monomer and trimer reflect this trend. Since, of course, there are other effects involved in the rate constant, such as steric effects, one cannot expect a quantitative correlation with charge. 


\section{ACKNOWLEDGEMENTS}

I wish to express my appreciation to Professor R. E. Connick who directed this research and in the process taught me something about thoroughness and completeness; to Dietmar Stehlik for the use of his pulse spectrometer; to Frank Papen and Phil Eggers for electronics assistance; to Tina Hulbert for secretarial assistance; to Reida officer for her line drawings; and to Jane Ball for her patience in typing this manuscript. Financial assistance from Woodrow Wilson National Fellowship Foundation and the Lawrence Radiation Laboratory is also greatly appreciated. This work was done under the auspices of the United States Atomic Energy Commission. 


\section{REFERENCES}

1. N. Bloembergen, E. M. Purcell, and R. V. Pound, Phys. Rev. B3, 679 (1948).

2. J. R. Zimmerman, J. Chem. Phys. 22, 950 (1954).

3. S. Broersma, J. Chem. Phys. 24, $659^{\circ}$ (1956).

4. A. W. Nolle and L. O. Morgan, J. Chem. Phýs. 26, 642 (1957).

5. R. E. Connick and R. E. Poulson, J. Chem. Phys. 30, 759 (1959).

6. T. J. Swift and R. E. Connick, J. Chem. Phys. 37, 307 (1962); ibid, $44,2553(1964)$.

7. R. A. Bernheim, T. H. Brown, H. S. Gutowsky, and D. E. Woessner, J. Chem. Phys. 30, 950 (1959).

8. R. A. Plane and H. Taube, J. Phys. Chem. 56, 33 (1952).

9. R. Hausser and G. Laukien, Z. Physik, 153, 394 (1959).

10. I. O. Morgan and A. W. Nolle, J. Chem. Phys. 31, 365 (1959).

11. N. Bloembergen and Li. O. Morgan, J. Chem. Phys. 34, 842 (196I).

12. T. J. Swift and T. A. Stephenson, Inorg. Chem., 5, 1100 (1966).

13. B. F. Melton and V. I. Pollak, J. Phys. Chem. T3, 3369 (1969).

14. Sister G. Thompson, Ph.D. Thesis, University of California, Berkeley Ca., UCRL-11410, June 1964.

15. R. W. Kolaczkowski and R. A. Plane, Inorg. Chem. 3, 322 (1964).

16. G. Schwarzenbach and B. Magyar, Helv. Chim Acta 45, 1425 (1962).

1\%. W. K. Wilmarth, H. Graff, and S. T. Gustin, J. Am. Chem. Soc. 78, $2683(1956)$.

18. See, for example, W. A. Anderson, "Measurement of Relaxation Times," in NMR and EPR Spectroscopy, the NMR-EPR Staff of Varian Associates, eds., Pergamon Press, New York, 1960, p. 169 ff, and references contained therein. 
19. J. A. Pople, W. G. Schneider and H. J. Bernstein, High - resolution Nuclear Magnetic Resonance, McGraw Hill Book Co., New York, 1959, p. 3 lff.

20. J. V. Acrivos, J. Chem. Phys. 36, 1097 (1962).

21. H. Y. Carr and E. M. Purcell, Phys. Rev. 24, 630 (1954).

22. A. Abragam, The Principles of Nuclear Magnetism, Oxford University Press, New York, 196l, p. 64.

23. J. A. Pople, W. G. Schnejder and H. J. Bernstein, High-resolution Nuclear Magnetic Resonance, McGraw Hill Book Co., New York, 1959, p. 86.

24. H. M. McConnell, J. Chem. Phys., 28, 430 (1958).

25. I. Solomon, Phys. Rev. 29, 559 (1955).

26. A. Abragam, op eit?., p. 334 .

27. R. E. Connick and D. Fiat, J. Chem. Phys. 44, 4103 (1966).

28. A. Abragam, op. cit., p. 306. ff.

29. N. Bioembergen, J. Shem. Phys, 27, 572 (1957).

30. A. Abragam, op. eit.,etc. p. 315.

31. N. Bloembergen, J. Chem. Phys. 27, 595 (1957).

32. J. A. Laswick and R. A. Plane, J. Amer. Chem. Soc. 81, 3564 (1959).

33. J. E. Finholt, Ph.D. Thesis, University of California, Berkeley, Ca. UCRI-8879, April 1960 .

34. G. W. Haupt, J. Res. NBS, 48, 414 (1952).

35. The author would like to express his appreciation and gratitude to Dr. Dietmar Stehlik and Professor E. H. Hahn of the Physics Department for the use of the pulse spectrometer and laboratory facilities.

36. Plots of chemical shifts of ethylene glycol and methanol vs temperature can be found in publication number 87-20:2-001 of Varian Associates, Palo Alto, California. 
37. G. Chiarotti and I. Giulotto, Phys. Rev. 23, 1241 (1954).

38. K. Kustin and J. Vriesenga, Inorganic Materials Research Division Annual Report 1968, Lawrence Radiation Laboratory, University of California, Berkeley, UCRL-18735, p. 14 .

39. Z. Luz and R. G. Shulman, J. Chem. Phys. 43, 3750 (1965).

40. J: J. Chang, University of California, Private communication.

41. See, for example, G. E. Pake, Paramagnetic Resonance, W.A. Benjamin, Inc., New York, 1962, p. 79 ff.

42. H. Brickweddie, J. Res., NBS 42, 309 (1949).

43. F. A. Cotton and G. Wilkinson, Advanced Inorganic Chemistry, Interscience Publ., 1962, p. 43 and 662.

44. R. Hausser and F. Noack, Z. Phys. I82, 93 (1964).

45. R. E. Connick and K. Wüthrich, J. Chem. Phys. 21,4506 (1969).

46. K. Wüthrich and R. E. Connick, Inorg. Chem. 6, 583 (1967):

47. M. R. Judkins, Ph.D. Thesis, University of California, Berkeley, California, UCRL-17561, May 1967.

48. M. V. Olson, Y. Kanazawa, and H. Taube, J. Chem. Phys. 51, 289 (1969).

49. W. L. Earl, Inorganic Materials Research Division, Annual Report 1968, Lawrence Radiation Laboratory, University of California, Berkeley, UCRL-18735, p. 16.

50. 3. Meiluoum, J. Chem. Phys. 34, 375 (1961).

51. A. Abragam, op sita. p. 302 .

52. M. Alei, Jr., Inorg. Chem. 3, 44 (1964).

53. R. T. Lee, Unpublished results. 
APPENDIX I: Experimental Dota for Trimer

A. $\quad 1 / \mathrm{T}_{2 \mathrm{p}}$ 's at $60 \mathrm{MHz}$ for five solutions of varying hydrogen ion and

trimer concentration as a function of reciprocal absolute temperature. Trimer concentration entered as moles per liter of chromium:

\begin{tabular}{|c|c|c|c|c|c|}
\hline Solution & {$\left[\mathrm{H}^{+}\right]$} & \multicolumn{2}{|c|}{$[\mathrm{Cr}(\mathrm{III})]$} & \multicolumn{2}{|c|}{$\mathrm{P}_{\mathrm{m}}^{\prime}$} \\
\hline 1. & 0.10 & \multicolumn{2}{|c|}{0.0632} & \multicolumn{2}{|c|}{$5.72 \times 10^{-4}$} \\
\hline 2 & 0.16 & \multicolumn{2}{|c|}{0.0626} & \multicolumn{2}{|c|}{$5.67 \times 10^{-4}$} \\
\hline 3 & 0.86 & \multicolumn{2}{|c|}{0.0627} & \multicolumn{2}{|c|}{$5.82 \times 10^{-4}$} \\
\hline 4 & 1.68 & \multicolumn{2}{|c|}{$0.0630^{\circ}$} & \multicolumn{2}{|c|}{$6.03 \times 10^{-4}$} \\
\hline 5 & 2.41 & \multicolumn{2}{|c|}{0.0633} & \multicolumn{2}{|c|}{$6.23 \times 10^{-4}$} \\
\hline \multirow{2}{*}{$10^{3} / \mathrm{T}^{\circ} \mathrm{K}$} & & $d / s$ & t $60 \mathrm{M}$ & & \multirow[b]{2}{*}{$5^{* *}$} \\
\hline & 1 & 2 & 3 & 4 & \\
\hline $3.50 / 3.51$ & 99.6 & 110.0 & 230.7 & 327.1 & 388.8 \\
\hline $3.64 / 3.66$ & 90.0 & 102.5 & 230.4 & 324.6 & 376.6 \\
\hline $3.53 / 3.51$ & 103.5 & 107.9 & 834.6 & 335.6 & 393.1 \\
\hline $3.38 / 3.39$ & 127.1 & 132.8 & 250.3 & 346.9 & 407.7 \\
\hline $3.28 / 3.28$ & 164.5 & 165.0 & 267.0 & 363.4 & 414.5 \\
\hline $3.18 / 3.13$ & 209.0 & $219: 4$ & 293.2 & 374.4 & 413.5. \\
\hline $3.00 / 3.00$ & 274.4 & 279.7 & 325.2 & 384.7 & 408.4 \\
\hline $3.39 / 3.41$ & 123.7 & 127.6 & 246.4 & 354.3 & 422.3 \\
\hline
\end{tabular}

*Values tabulated are the averages of many determinations. $* * *$

Numbers at the top of columns correspond to particular solutions. 
B. $1 / \mathrm{T}_{2 \mathrm{p}}$ 's at 60 and $100 \mathrm{MHz}$ for the same solution as a, function of reciprocal absolute temperature

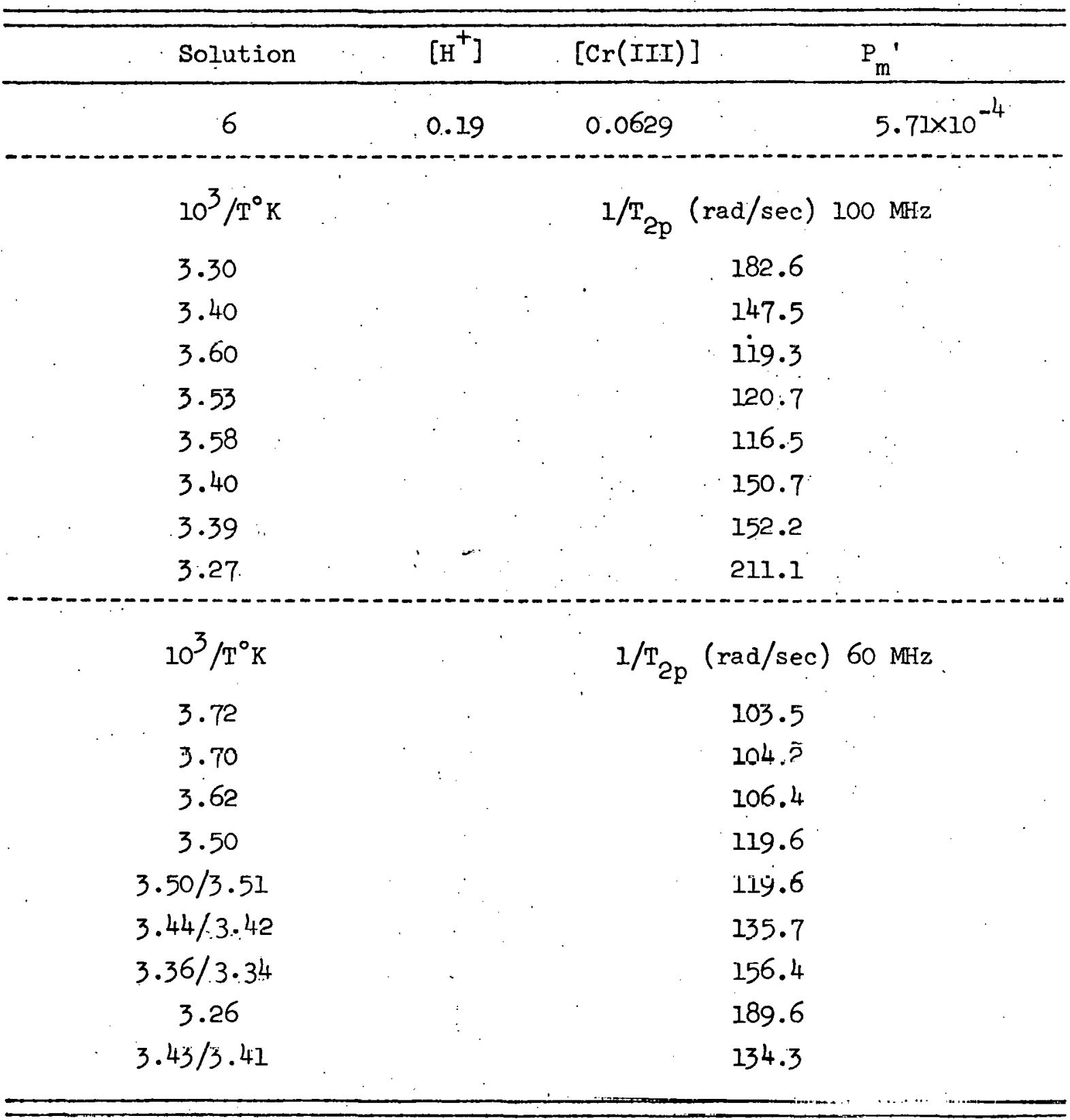


C. Chemical shifts at $60 \mathrm{MHz}$ as a function of reciprocal absolute temperature.

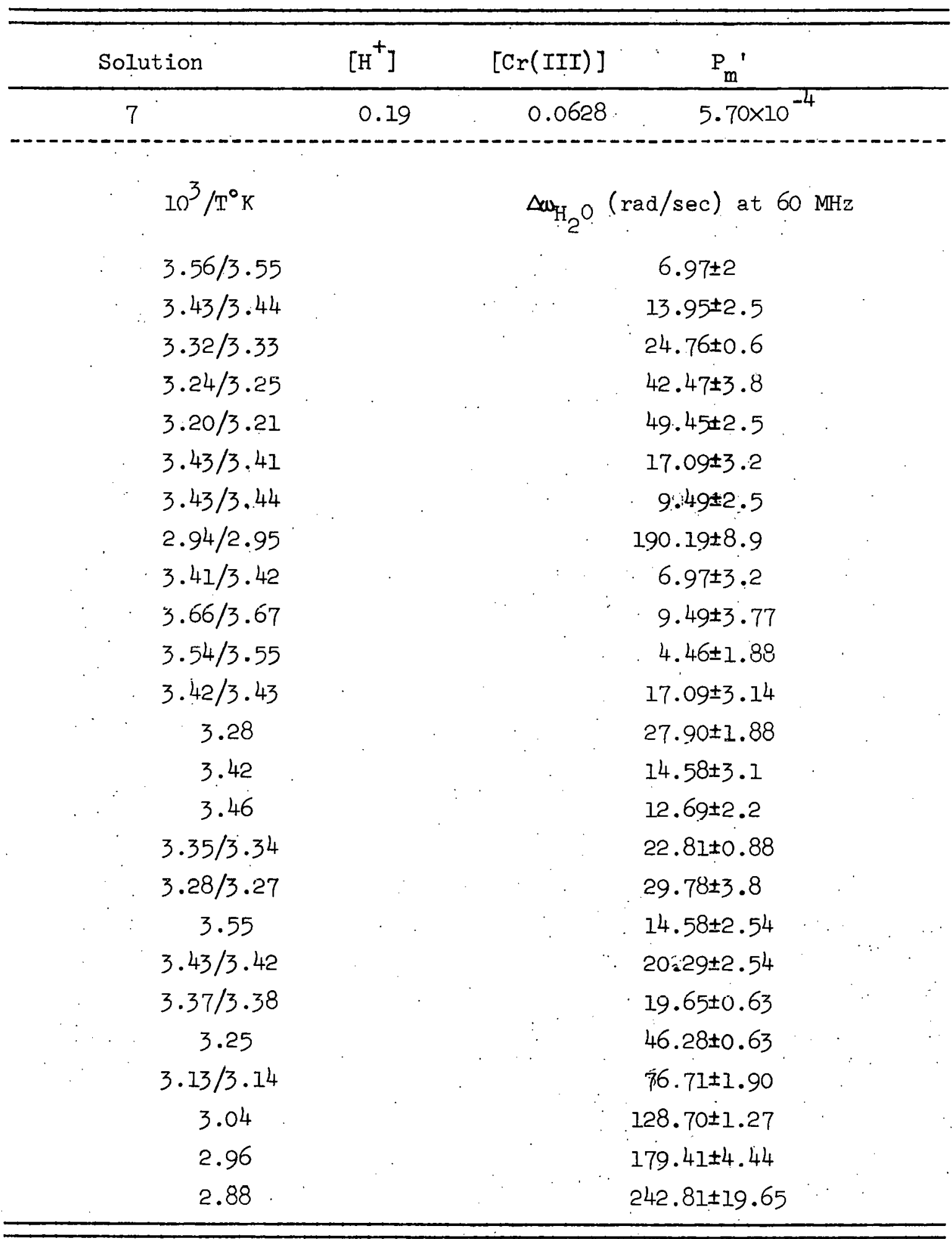


D. $\mathrm{T}_{\text {Ip }}$ 's at $11 \mathrm{MHz}$ for three solutions of varying hydrogen ion and trimer concentration as a function of reciprocal absolute temperature.

\begin{tabular}{cccc}
\hline Solution & {$\left[\mathrm{H}^{+}\right]$} & {$[\mathrm{Cr}(\mathrm{III})]$} & $\mathrm{P}_{\mathrm{m}}^{\prime}$ \\
\hline 8 & 0.17 & 0.0626 & $5.68 \times 10^{-4}$ \\
9 & 0.17 & 0.1249 & $11.34 \times 10^{-4}$ \\
10 & 1.56 & 0.0624 & $5.93 \times 10^{-4}$
\end{tabular}

$\mathfrak{T}_{1 \mathrm{p}}($ millisec) at $11 \mathrm{MHz}$

$\begin{array}{cccc}10^{3} / \mathrm{T}^{\circ} \mathrm{K} & 8 & 9 & 10 \\ 3.66 & 13.5 & 6.7 & 7.4 \\ 3.73 & 13.2 & 6.5 & 7.4 \\ 3.65 & 13.5 & 6.5 & 7.4 \\ 3.65 & & 6.6 & \\ 3.55 & 13.4 & 6.6 & 7.5 \\ 3.42 & 11.8 & & \\ 3.42 & 12.3 & 6.2 & 7.4 \\ 3.32 & 11.2 & 5.5 & 7.6 \\ 3.20 & 10.1 & 5.0 & 7.9 \\ 3.41 & 11.7 & 5.7 & 7.4 \\ 3.18 & 9.4 & 4.8 & 7.9 \\ 3.10 / 3.12 & 9.1 & 4.4 & 7.6 \\ 3.42 & 11.9 & 5.8 & \\ 3.84 & 9 & & \end{array}$

* Tabulated longitudinal relaxation times were determined as mentioned in text. 


\section{FIGURE CAPTIONS}

1. Proposea structures for the chromium polymers. The chromium atoms are localed at the centers of the octahedra. Water molecules are located at the apices while the hydroxo bridging groups are located at the ends of the shared edges. Equivalent water molecules are indicated with the same letter. a) Dimer, b) Trimer-straight linear, c) Trimer-offset Iinear, and d) Trimer-cyclic.

2. $\Delta \mathrm{w}_{\mathrm{H}_{2} \mathrm{O}} / \mathrm{P}_{\mathrm{m}}(\mathrm{rad} / \mathrm{sec})$ vs. the reciprocal of the absolute temperature at $60 \mathrm{MHz}$ for a solution of trimer where $[\mathrm{Cr}(\mathrm{III})]=0.063 \mathrm{M}$ and $\left[\mathrm{H}^{+}\right]=0.19 \mathrm{M}$. The solid line corresponds to calculated values. as explained in the text

$$
\mathrm{P}_{\mathrm{m}}=\frac{2 \mathrm{O} / 3[\mathrm{Cr}(\mathrm{III})]}{2\left[\mathrm{H}_{2} \mathrm{O}\right]+\left[\mathrm{H}^{+}\right]}
$$

3. $1 / T_{2 p_{m}} P_{m}^{\prime}(\mathrm{rad} / \mathrm{sec})$ vs. the reciprocal of the absolute temperature at $60 \mathrm{MHz}$ for three solutions of trimer all $0.063 \mathrm{M}$ in chromium but differing in acidity. $\nabla-2.41 \mathrm{M}$ in $\left.\mathbb{H}^{\dagger}\right] ;+-1.68 \underline{\mathrm{M}}$ in $\left.\mathrm{H}^{+}\right]$; in $\mathrm{H}^{+}$.- The solid lines correspond to calculated values as explained in the text.

$$
\mathrm{P}_{\mathrm{m}}^{\prime}:=\frac{[\mathrm{Cr}(\mathrm{III})]}{2\left[\mathrm{H}_{2} \mathrm{O}\right]+\left[\mathrm{H}^{+}\right]}
$$

4. $I / \mathrm{T}_{1 \mathrm{p}} \mathrm{P}_{\mathrm{m}}^{\prime}(\mathrm{rad} / \mathrm{sec})$ vs. the reciprocal of the absolute temperature at $11 \mathrm{MHz}$ for three solutions of trimer.

$$
\begin{array}{ccc} 
& {\left[\mathrm{IH}^{+}\right]} & {[\mathrm{Cr}(\mathrm{III})]} \\
0 & 0.17 & 0.063 \\
+ & 0.17 & 0.125 \\
\Delta & 1.56 & 0.062
\end{array}
$$

The two upper solid lines correspond to calculations for just the first cuurdination sphere. The lower set of t's is the difference between the 
experimental data for the $0.17 \mathrm{M}$ acid solutions and the calculated line to yield the second coordination sphere contribution. The bottom solid line is an attempt to fit this contribution as explained in the text. $P_{m}^{\prime}$ was defined previously.

5. Assumed temperature dependence of $1 / T_{12}$ at 2,586 gauss (corresponding to $11 \mathrm{MHz}$ for protons) added to the assumed temperature dependence of $I / \tau_{r}$ to yield $I / \tau_{I}$ for trimer.

o. Calculated values for $1 / T_{I S}$ for trimer as explained in the text. Derived values for $I / T_{I D}$ as explained in the text. Both sets are done for a field corresponding to $1 \mathrm{MHz}$ for protons.

7. Assumed temperature dependence of $1 / T_{1 e}$ for trimer at 2,586 gauss (corresponding to $11 \mathrm{MHz}$ for protons) and the derived temperature dependence of $1 / \mathrm{T}_{\text {le }}$ at 14,000 gauss ( $60 \mathrm{MHz}$ for protons) as explained in the text.

8. The temperature dependence of $I / T$ le for monomer at the two fields correoponding to 11 and $60 \mathrm{MIz}$, calculated accuralng lo the data given by Melton and Pollak.

Y. I'he sum of $1 / T_{I e}$ at. 14,000 gauss and $I / \tau_{r}$ to yield $I / \tau_{I}$ for trimer as a. function of temperature.

10. The sum of $1 / T_{2 S}$ and $I / T_{2 D}$ to yield $1 / T_{2 m}$ for trimer at 14,000 gauss as a function of temperature.

II. Calculated values of $\Delta_{\mathrm{m}}{ }^{2} \tau_{\mathrm{m}}$ for five acidities at $60 \mathrm{MHz}$ for trimer. irom top to bottom, the acidities in moles per liter are $\Delta-0.10$; $0-0.16 ; \square-0.86 ;+-1.68 ;$. and $\nabla-2.41 .1 / \mathrm{T}_{2 \mathrm{~m}}$ at $60 \mathrm{MHz}$ is also shown.

je. $I / \mathrm{T}_{2 \mathrm{p}} \mathrm{P}_{\mathrm{m}}(\mathrm{rad} / \mathrm{sec})$ vs. the reciprocal of the absolute temperature at 60 Miz for three solutions of trimer, all $0.063 \mathrm{M}$ in chromium 
but differing in acidity: $+-0.19 \mathrm{M}, \oplus-0.16 \mathrm{M}, \Delta-0.10 \underline{\mathrm{N}_{1}}$ in $\left[\mathrm{H}^{+}\right]$. $\square$.refers to the same solution as + but the data were taken at $100 \mathrm{MHz}$. The three upper lines correspond to calculations for just the first coordination sphere. The, lower points are merely the differences between the experimental data and the calculated lines to yield the second coordination sphere contribution. The lower solid line corresponds to an attempt to fit this contribution as explained in the text. 


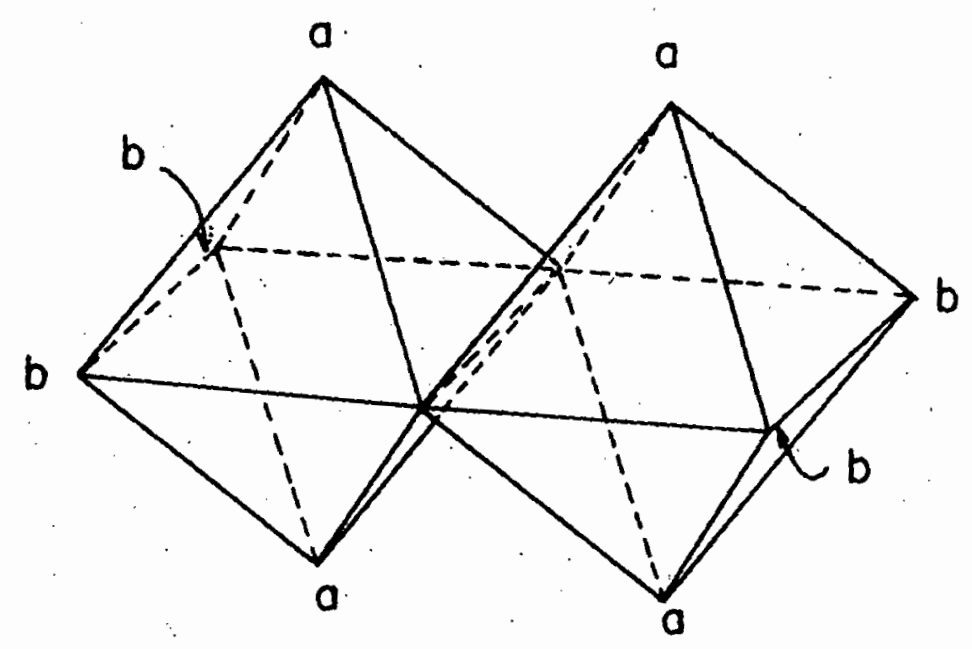

A

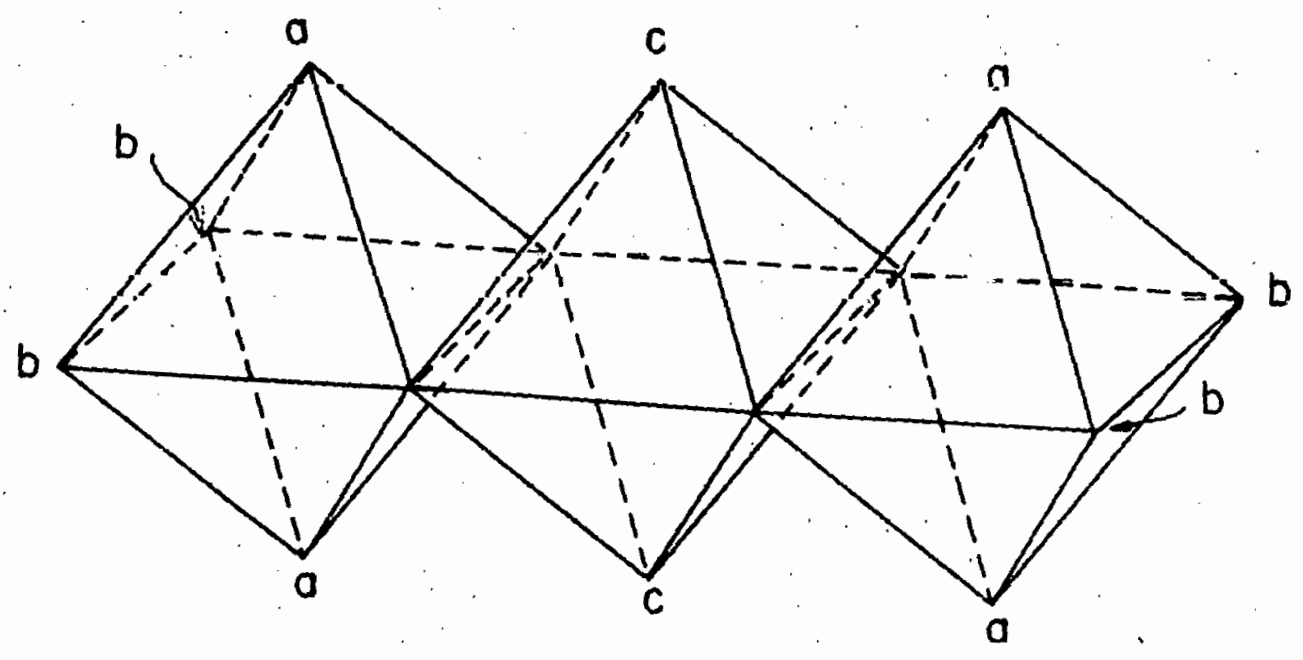

B

XBL 707-1605

Figure 1 


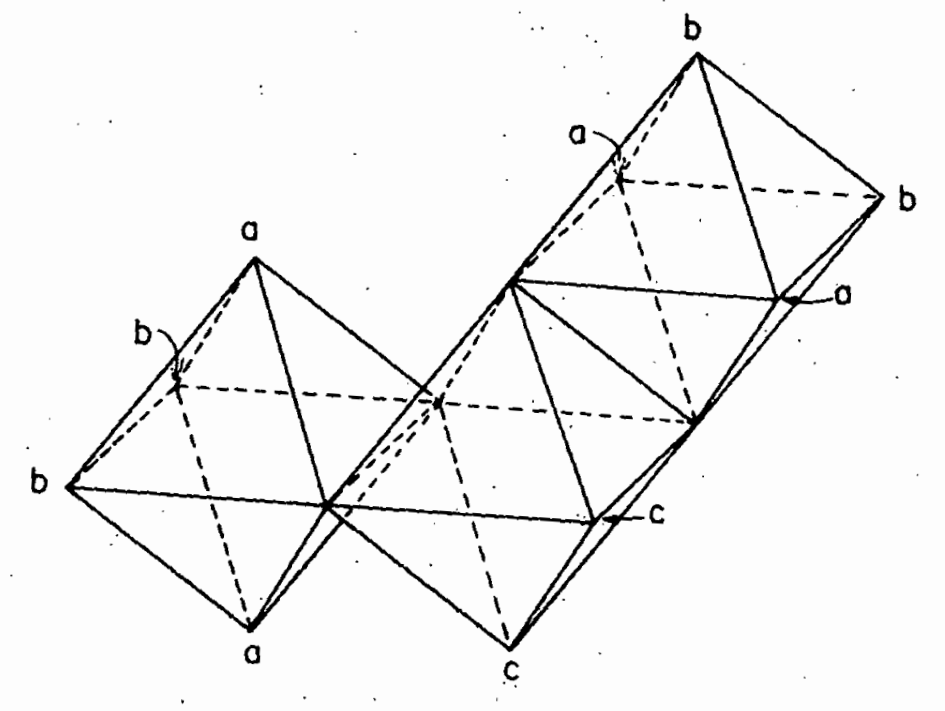

C

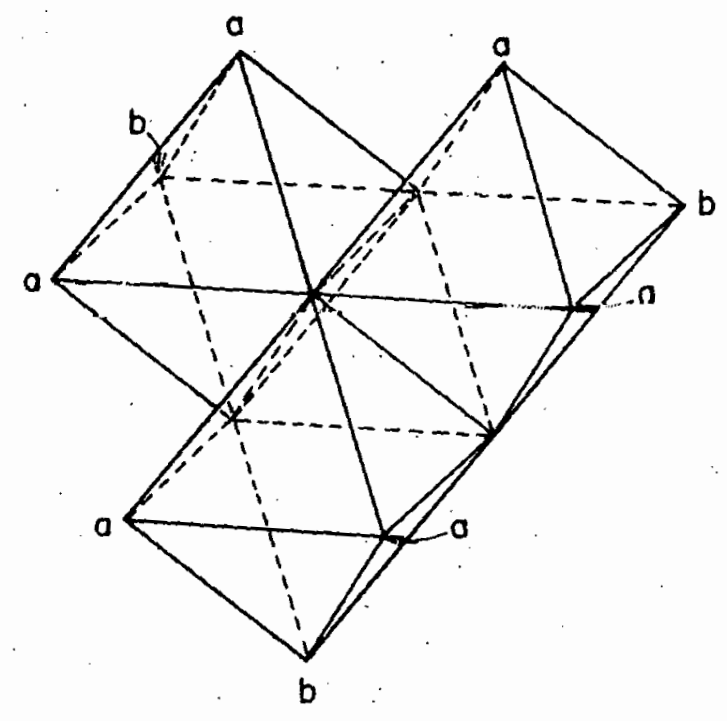

D

XBL 707-1606

Figure 1 continued 


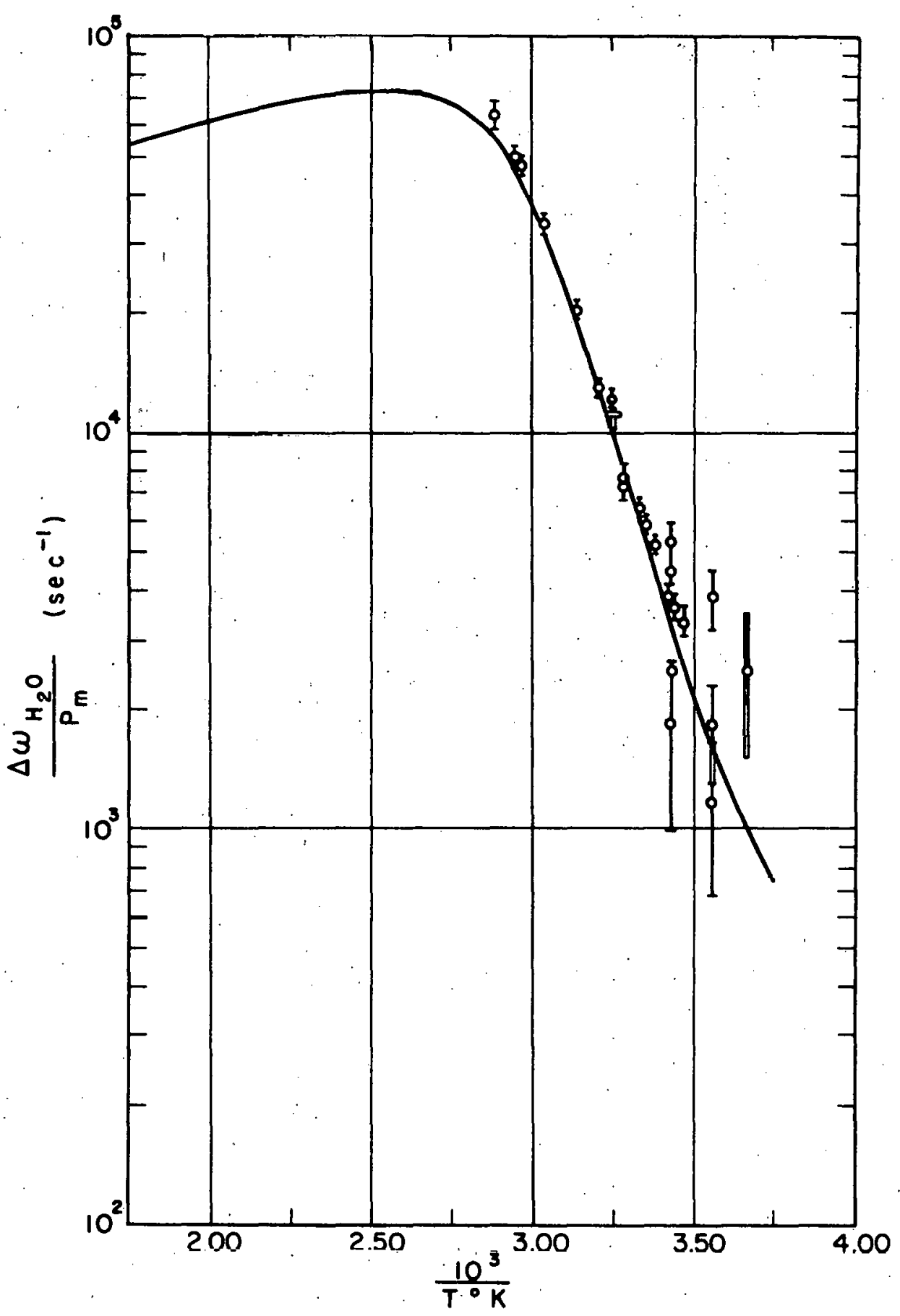

XBL 707-1609

Figure 2 


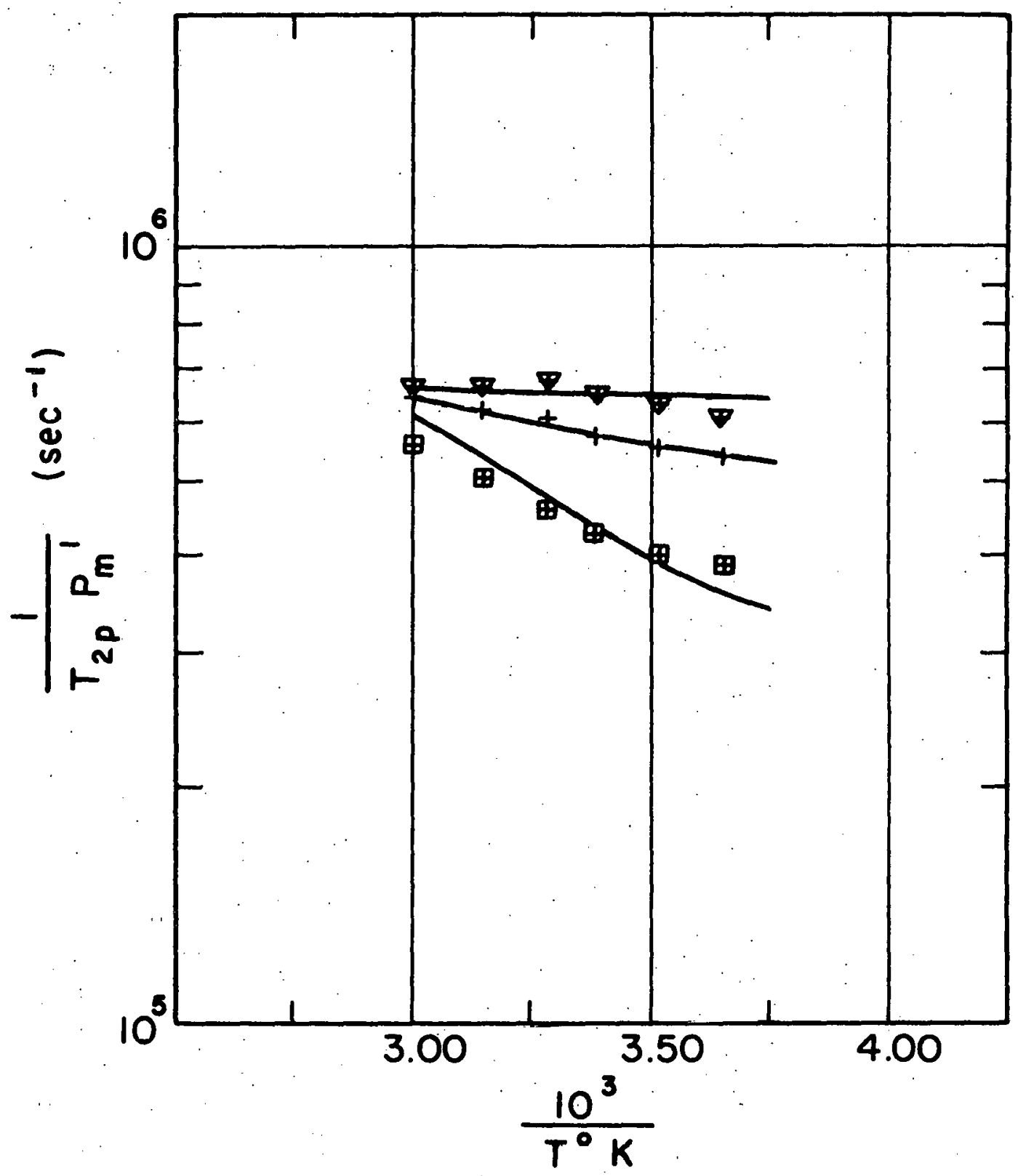

XBL $707-1610$

Figure 3 
$-74-$

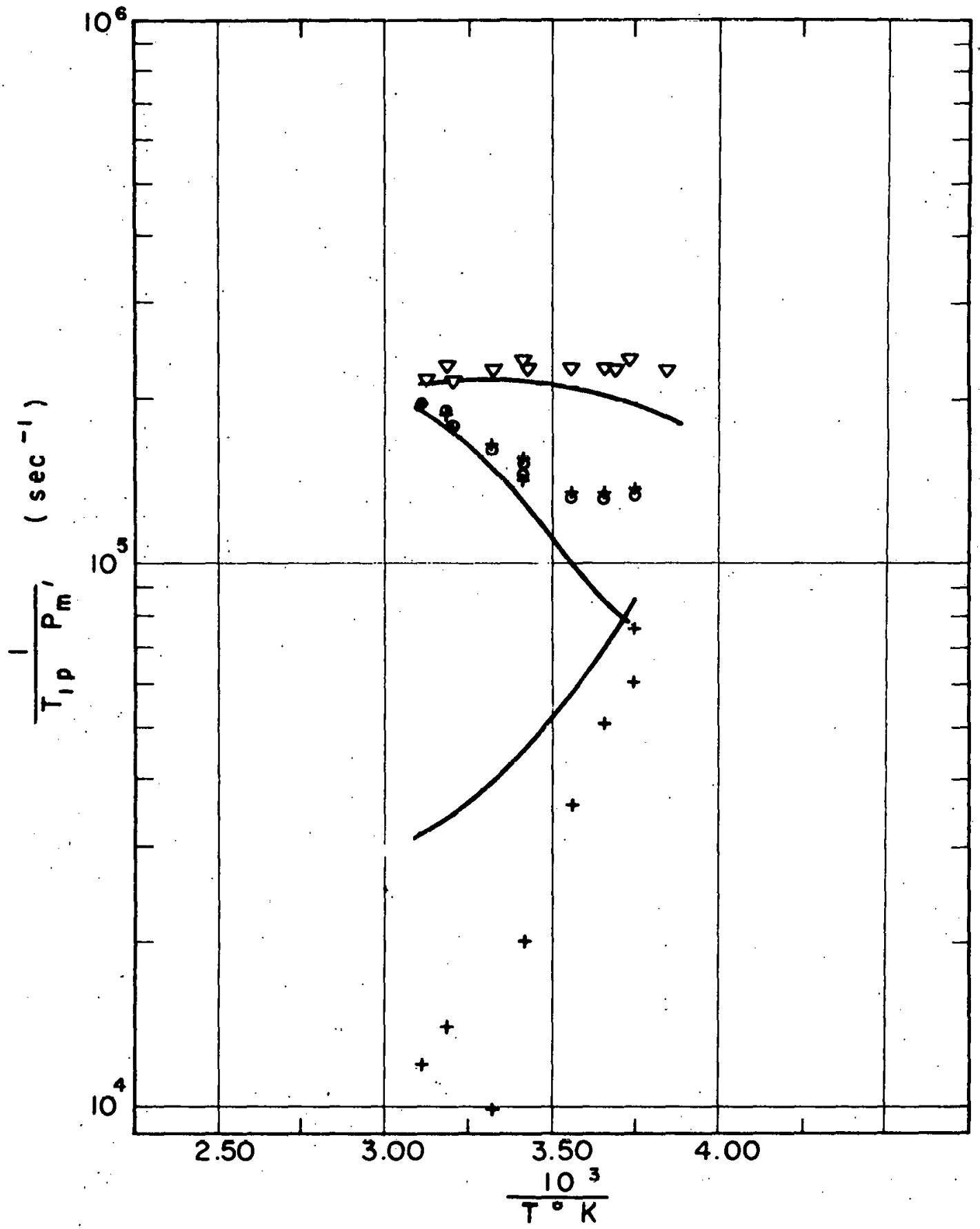

XBL $707-1607$

Figure 4 


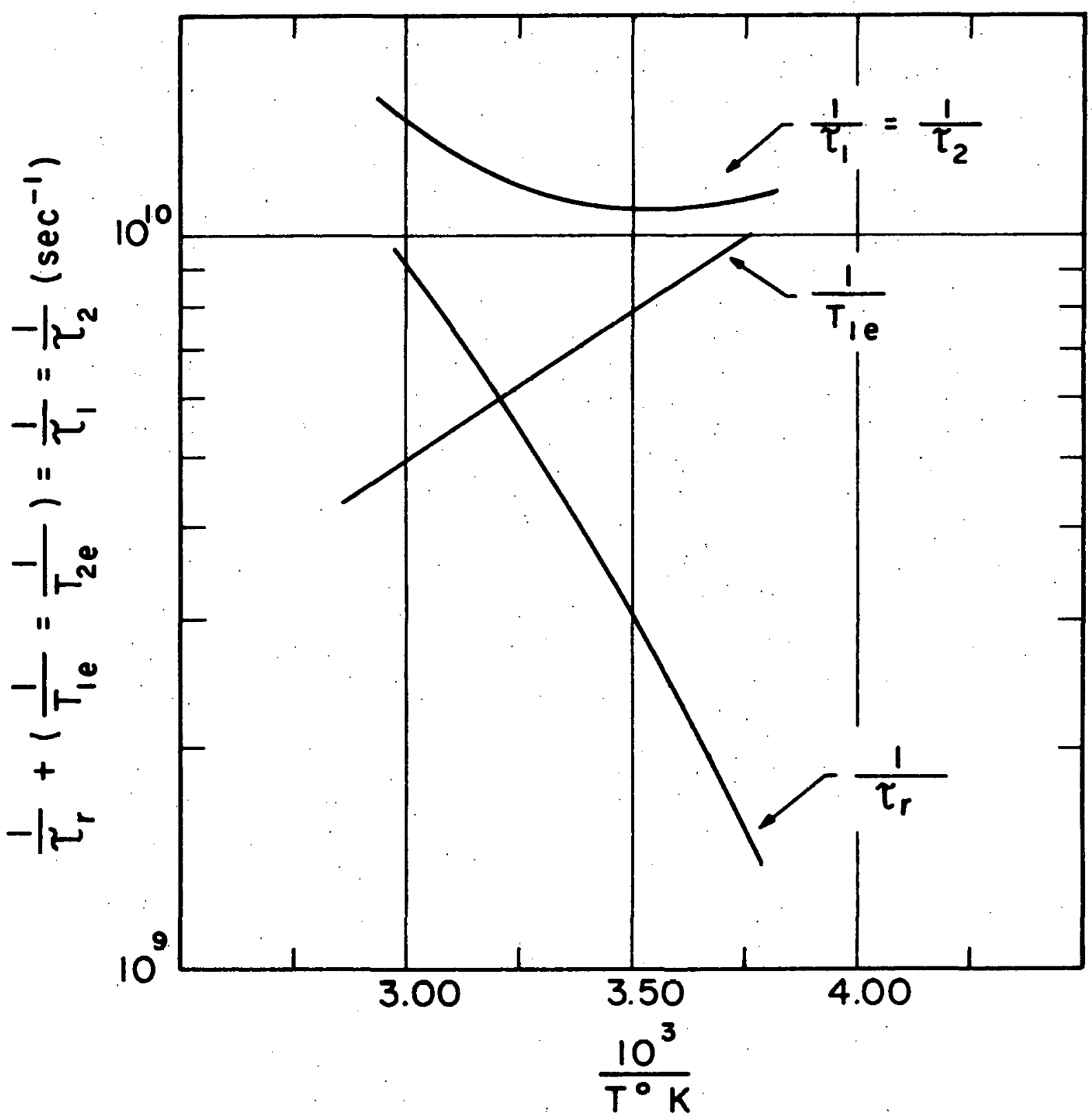

XBL $707-1608$

Figure 5 


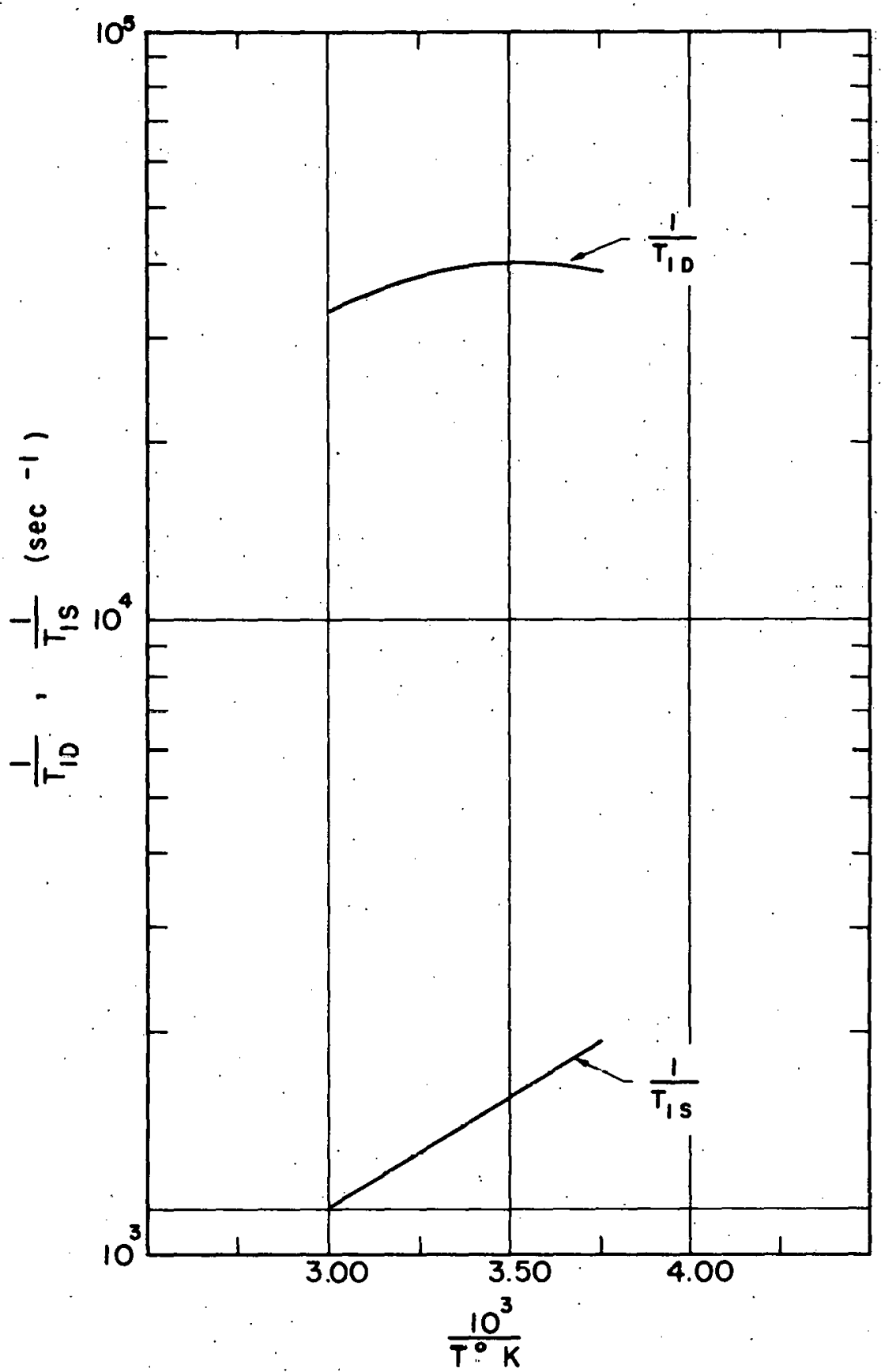

XBL 707-1611

Figure 6 


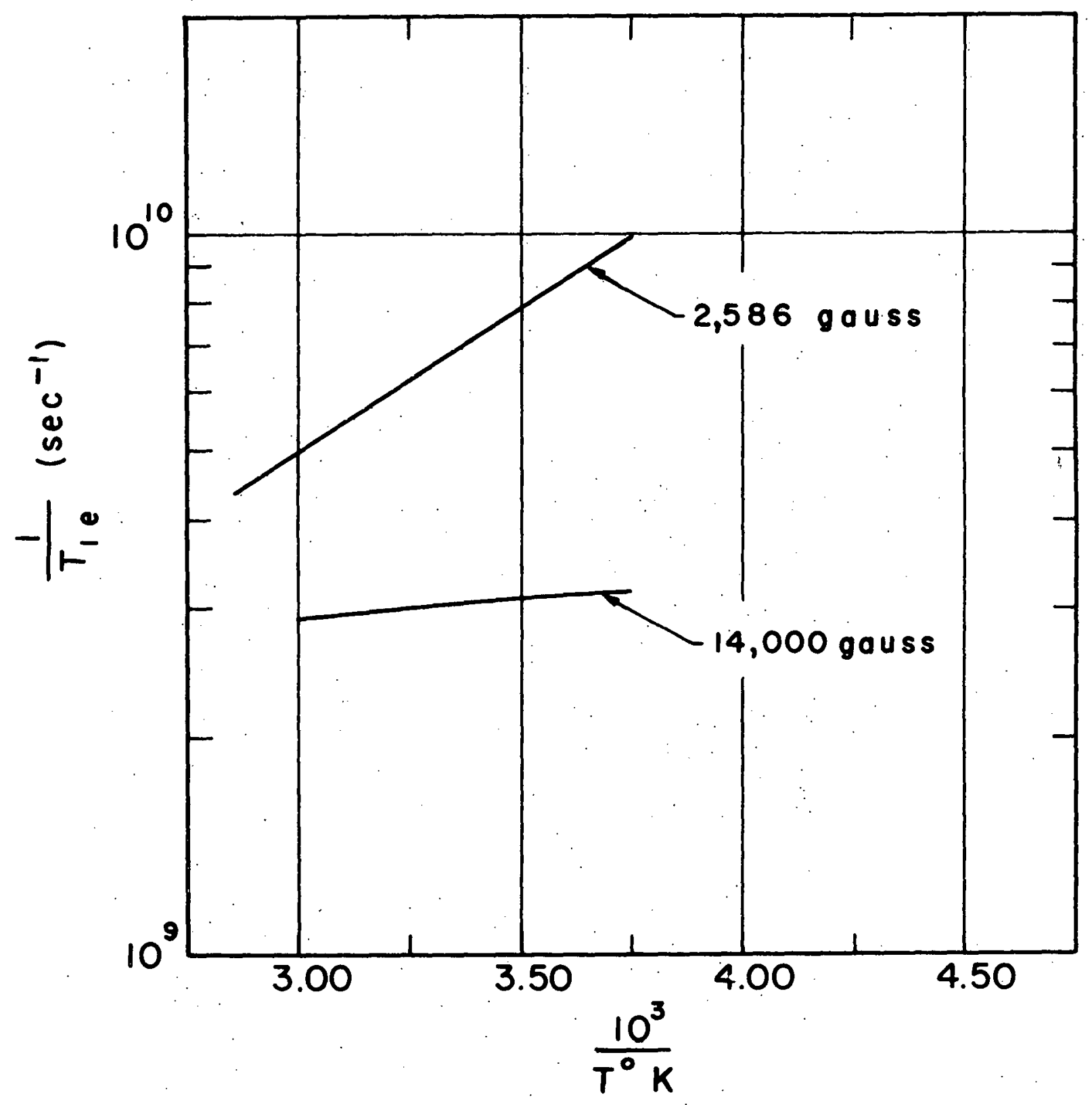

XBL 707-1612

Figure 7 


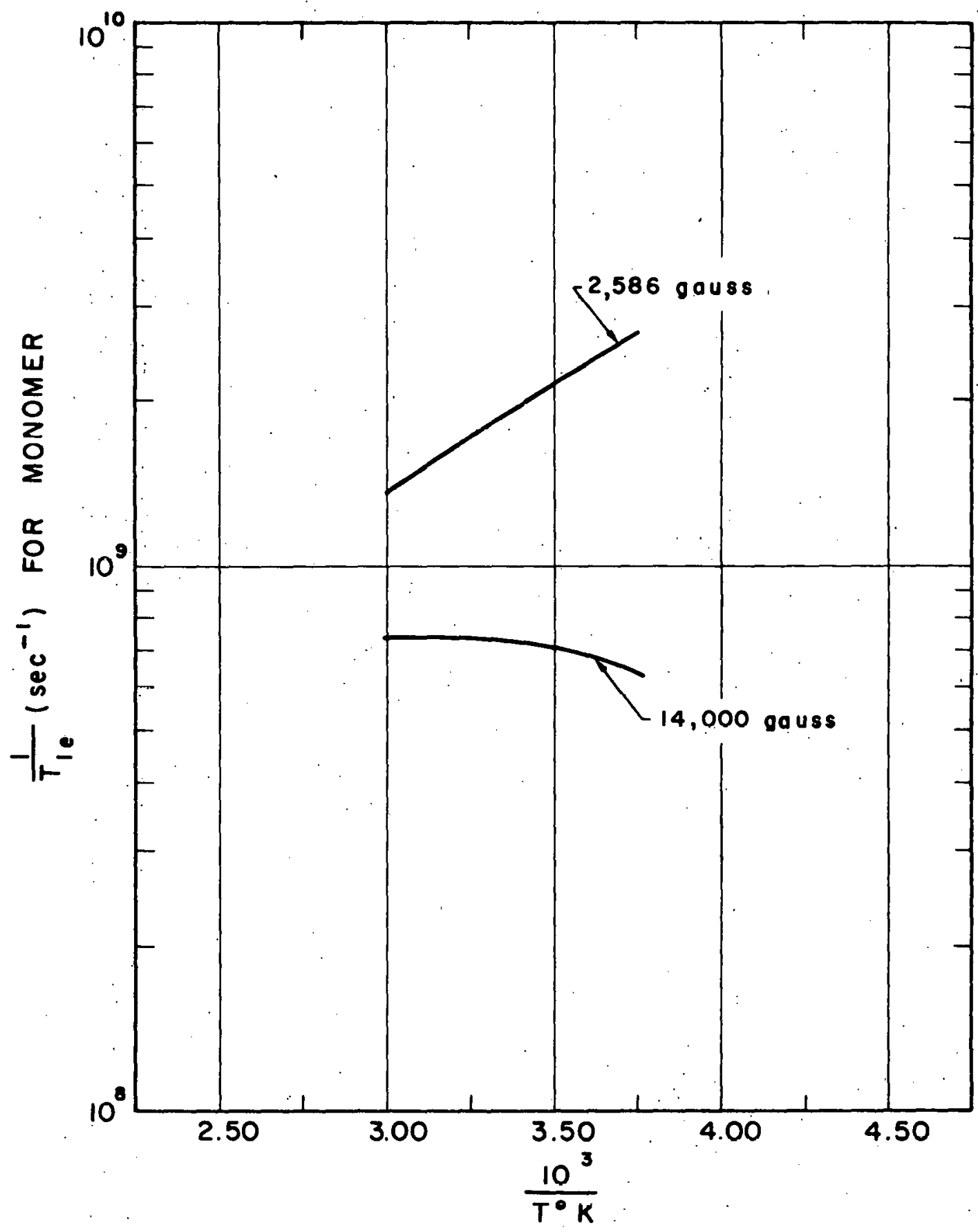

XBL $707-1613$

Figure 8 


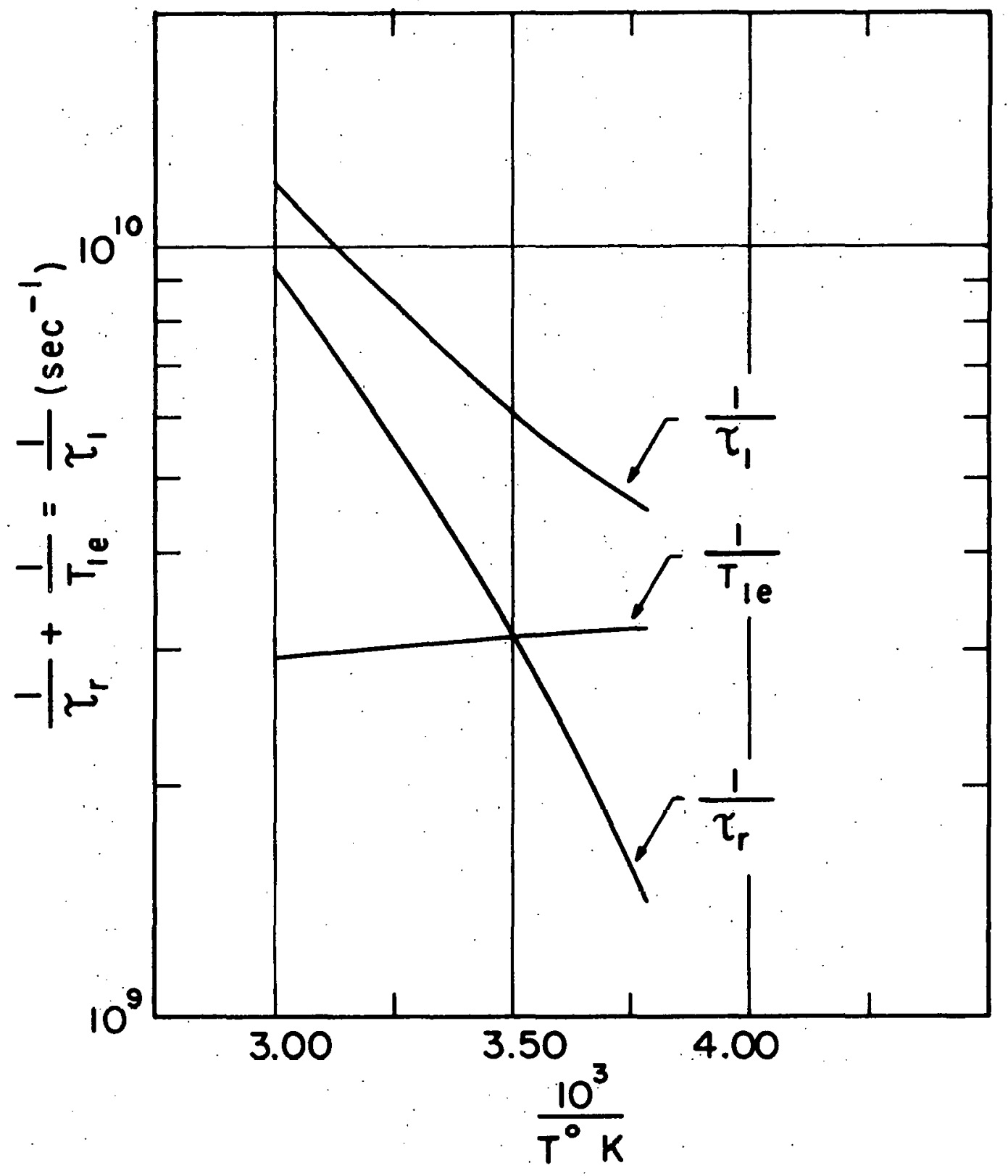

XBL 707-1614

Figure 9 


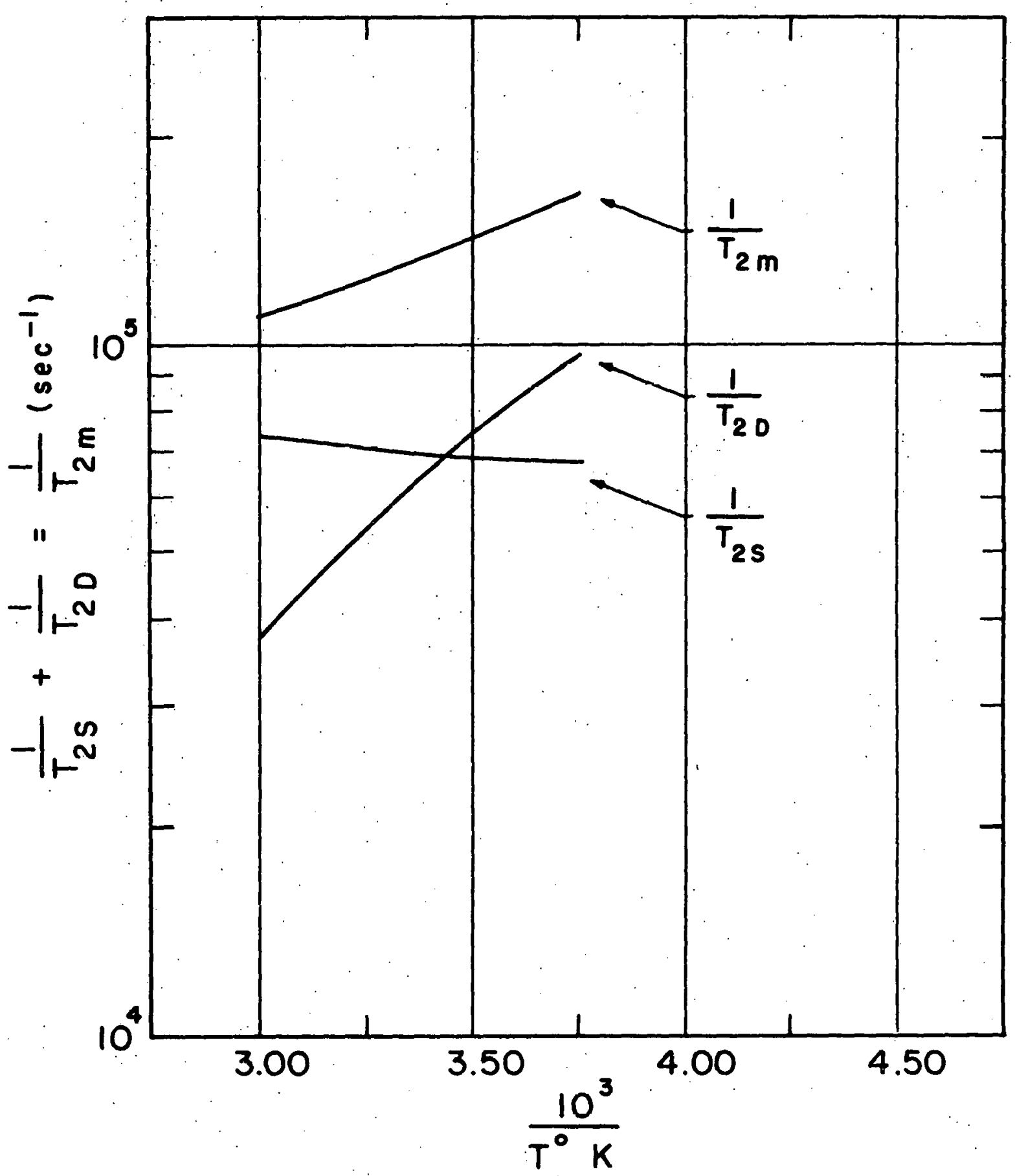

XBL $707-1615$

Figure 10 


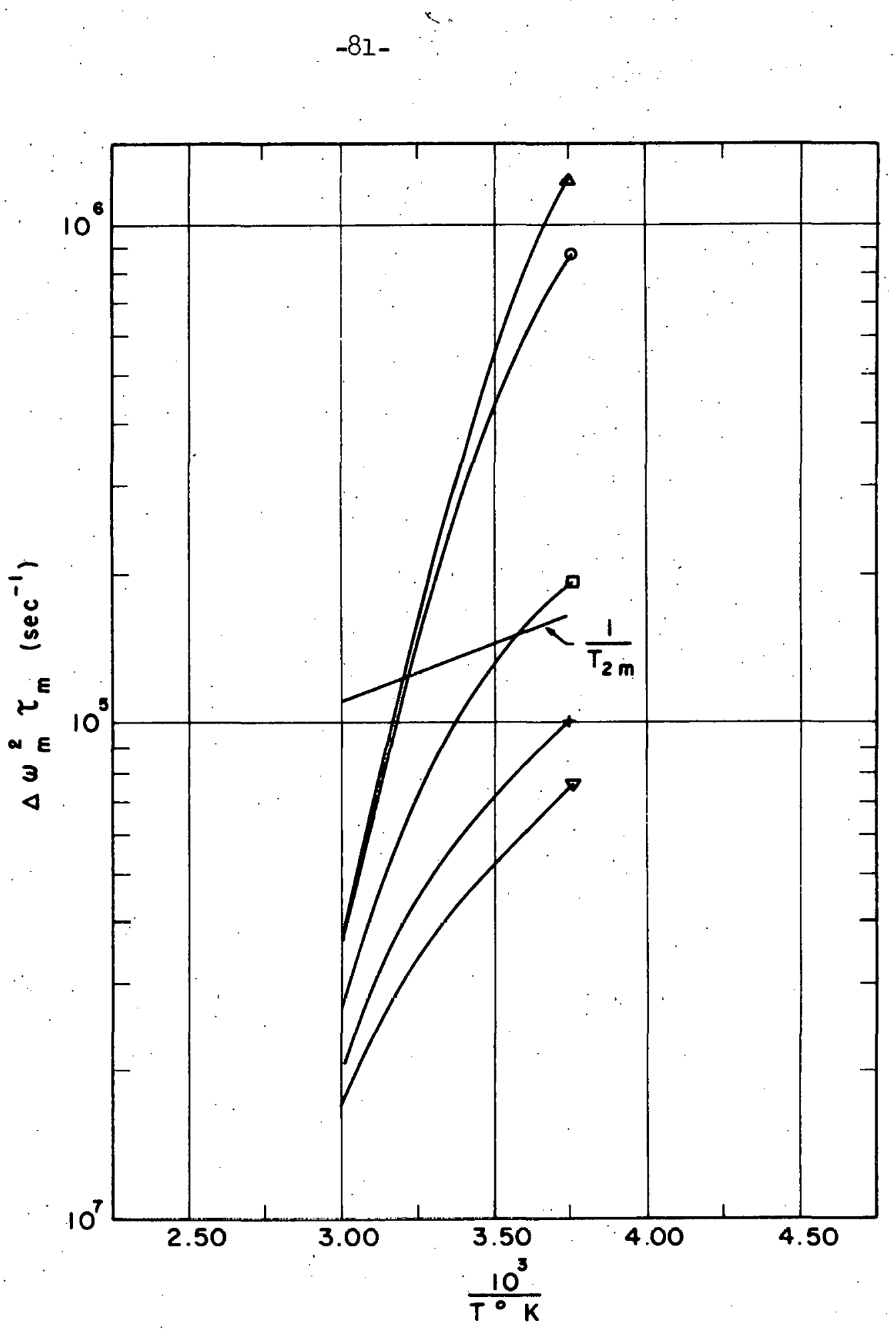

XBL 707-1616

Figure 11 


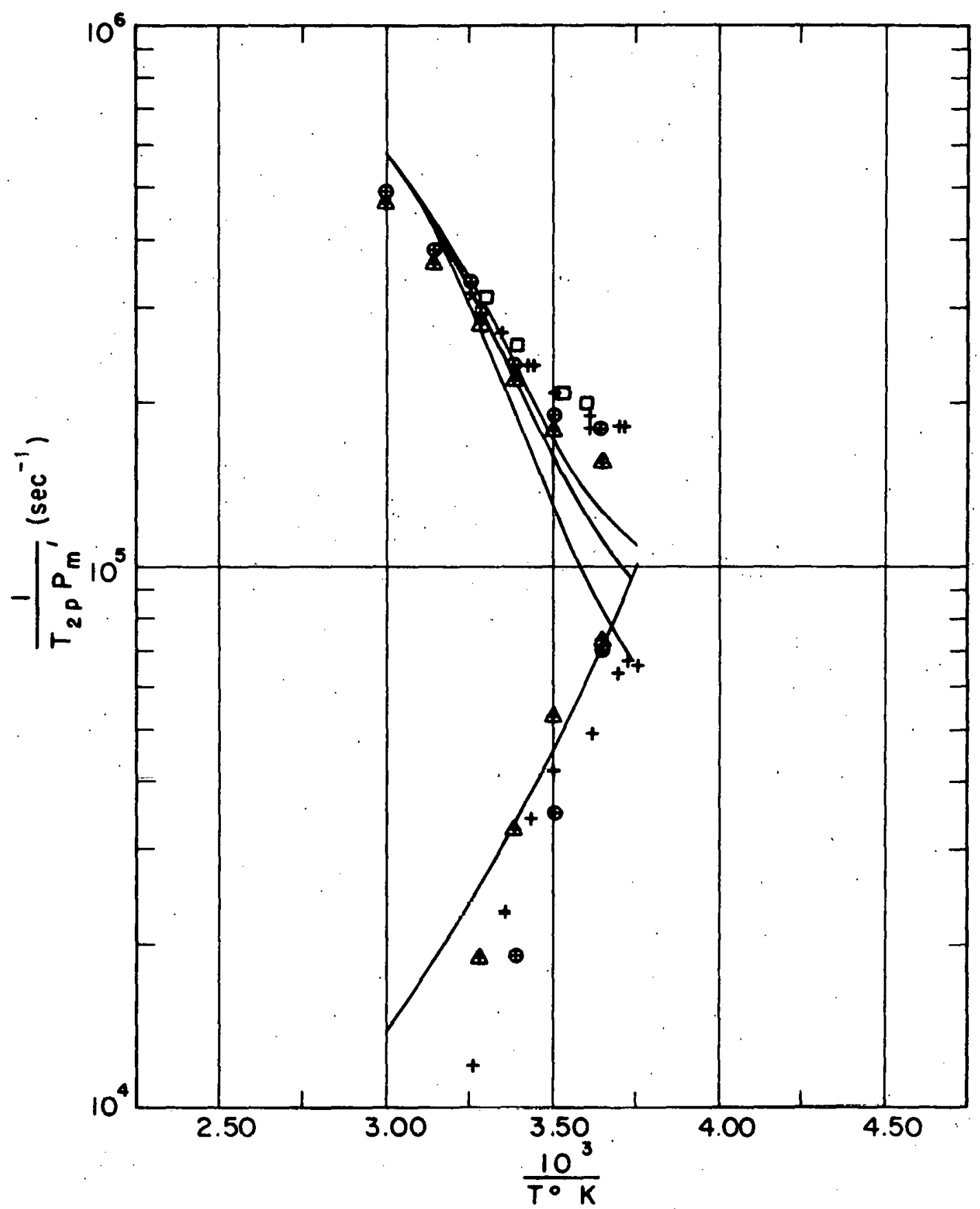

XBL 707-1617

Figure 12 


\section{LEGAL NOTICE}

This report was prepared as an account of Government sponsored work. Neither the United States, nor the Commission, nor any person acting on behalf of the Commission:

A. Makes any warranty or representation, expressed or implied, with respect to the accuracy, completeness, or usefulness of the information contained in this report, or that the use of any information, apparatus, method, or process disclosed in this report may not infringe privately owned rights; or

B. Assumes any liabilities with respect to the use of, or for damages resulting from the use of any information, apparatus, method, or process disclosed in this report.

As used in the above, "person acting on behalf of the Commission" includes any employee or contractor of the Commission, or employee of such contractor, to the extent that such employee or contractor of the Commission, or employee of such contractor prepares, disseminates, or provides access to, any information pursuant to his employment or contract with the Commission, or his employment with such contractor. 
